\title{
Variations of topside ionospheric electron density near the dawn terminator in relation to geomagnetic activity
}

\author{
Sunny W.Y. Tam ${ }^{1, *}$, Chien-Han Chen ${ }^{1,2}$ and Kaiti Wang ${ }^{3}$ \\ ${ }^{1}$ Institute of Space and Plasma Sciences, National Cheng Kung University, Tainan, Taiwan \\ 2 Now at National Property Administration, Ministry of Finance, Taiwan \\ ${ }^{3}$ Department of Aerospace Engineering, Tamkang University, New Taipei City, Taiwan
}

Received 30 April 2017 / Accepted 20 October 2017

\begin{abstract}
A statistical study to determine the influence of geomagnetic disturbances on the ionosphere across the dawn terminator at subauroral and middle latitudes is performed, based on the vertical electron density profiles measured by the GPS Occultation Experiment aboard the FORMOSAT-3/COSMIC satellites from August 2006 to July 2009. Three ranges of solar zenith angles are adopted to characterize transitions between the pre- and post-dawn ionosphere. Results indicate opposing plasma density effects at the darkened and sunlit locations between $50^{\circ}$ and $65^{\circ}$ magnetic latitude $\left(\lambda_{m}\right)$. The darkened topside ionosphere features density increases associated with geomagnetic activity, while density reductions mark its sunlit counterpart. The average electron peak density in the F2 region can increase by up to $44 \%$ in the darkened ionosphere and decrease by up to $20 \%$ in the sunlit ionosphere as $K p$ changes from $0-1$ to $4-5$. In the $\lambda_{m}=55^{\circ}-65^{\circ}$ range, the dominant contributors to the density perturbation are auroral electron precipitation for the darkened region and enhanced penetration electric fields for the sunlit region, with the transition occurring across the terminator local times. Dominance shifts first to electric fields at $50^{\circ}-55^{\circ}$, then to aurora-induced neutral wind at $45^{\circ}-50^{\circ}$, suggesting that during disturbed times electric fields seldom penetrate below $\lambda_{m}=50^{\circ}$. Findings presented in this statistical study should contribute to the study of space weather and the understanding of non-local influences of geomagnetic disturbances on topside dynamics.
\end{abstract}

Keywords: solar zenith angle / penetration electric fields / auroral electron precipitation / neutral wind / dawnside ionosphere

\section{Introduction}

As human activities increasingly rely on space-based technology, accurate prediction of the influence of geomagnetic disturbances on the topside ionosphere has become ever more important. Unfortunately, that is difficult to achieve for subauroral and middle magnetic latitudes. Previously reported observations showed that at these latitudes the ionosphere manifests positive and negative plasma density perturbations during periods of geomagnetic activity (e.g. Buonsanto, 1999; and references therein). The observed positive and negative perturbations are responses to multiple driving mechanisms associated with geomagnetic disturbances. For example, positive density effects may be due to traveling atmospheric/ionospheric disturbances (Prölss \& Jung, 1978; Cai et al., 2012), variations in the global wind circulation (Jones \& Rishbeth, 1971; Ngwira et al., 2012), expansion of the region

*Corresponding author: sunwytam@mail.ncku.edu.tw of auroral particle precipitation (Mikkelsen, 1975; Hardy et al., 2008), and/or enhanced plasma convection (Foster, 1993; Heelis et al., 2009). While the last of the aforementioned mechanisms may sometimes cause ionospheric densities to decrease (Astafyeva et al., 2016), negative perturbations on the density can also be associated with variations in thermospheric compositions (Taeusch et al., 1971; Goncharenko et al., 2006), equatorward migrations of mid-latitude troughs (Brace et al., 1974; Shagimuratov et al., 2002), and/or increased ion and neutral temperatures that enhance recombination rates (Thomas \& Norton, 1966; Pavlov \& Buonsanto, 1997).

Physical mechanisms responsible for density perturbations during periods of enhanced geomagnetic activity were mostly identified through case studies of individual storm or substorm events (e.g. Basu et al., 2001; Goncharenko et al., 2006). By tracking plasma properties at given ionospheric locations throughout disturbed periods, the case-study approach can reveal critical details about the local changes that allow investigators to identify causative physical mechanisms. Case studies are essential for identifying and quantifying the diverse 

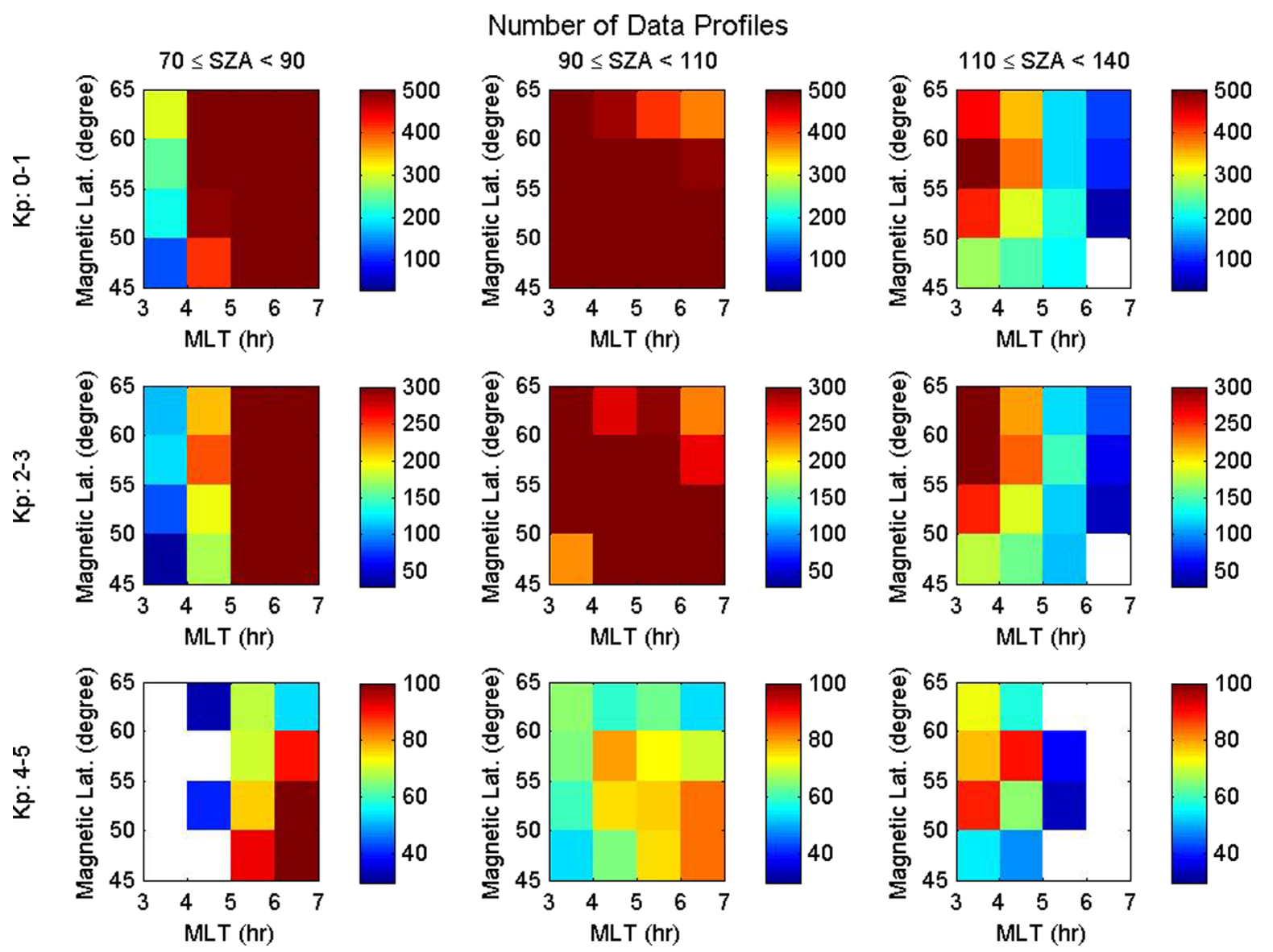

Fig. 1. Color plots indicating the number of EDPs in each data group sorted by solar zenith angle (SZA), Kp index, magnetic latitude, and MLT. White indicates groups with $\leq 30$ profiles.

and competing mechanisms that can operate in the ionosphere during periods of high geomagnetic activity. However, if one were to predict how future geomagnetic disturbances would perturb the topside ionosphere at subauroral and middle latitudes where plasma densities may increase/decrease in response to the different driving mechanisms (Klimenko et al., 2012), it is essential to have knowledge about which of the competing mechanisms is most likely to be dominant under the specific ionospheric conditions and to anticipate the positive or negative local density responses accordingly. The required practical knowledge can only be obtained through observationally based statistical studies.

This study examines the statistical properties of perturbations in vertical electron density profiles (EDPs) observed near the dawn meridian at subauroral latitudes due to geomagnetic activity. The studied EDPs, corresponding to the solarminimum period between August 2006 and July 2009, were measured by the GPS occultation experiment (GOX) aboard the FORMOSAT-3/COSMIC (F3C) satellites based on radio occultation (RO) techniques for probing the ionosphere (Schreiner et al., 1999). The objectives of this study are to identify typical trends of density perturbations in the local ionosphere and establish their statistical properties as indicators of locally dominant, disturbance mechanisms. Section 2 presents statistical results of EDP analyses that demonstrate qualitatively different density perturbations develop in the topside ionosphere before and after daybreak. Section 3 extends our analyses to investigate the possible roles that plasma transport mechanisms play in the formation of density perturbations. A discussion of our findings and conclusions is provided in Section 4.

\section{Statistical analysis of local density perturbations}

The FORMOSAT-3/COSMIC mission consists of a constellation of six identical micro-satellites (Cheng et al., 2006). Vertical EDPs obtained from GOX aboard the F3C satellites cover a broad range of locations in the global ionosphere. Similar to the approach by Wang \& Tam (2010), in which EDPs were sorted using combinations of three independent parameters: magnetic latitude, magnetic local time, the Dst index - in their study of the effects of geomagnetic disturbances on the low-latitude ionosphere, this study combines four sorting criteria to divide EDPs into 144 groups. The first two parameters are magnetic latitude $\lambda_{m}$ (henceforth simply referred to as "latitude") and magnetic local time (MLT). This study examines the locations in the northern hemisphere across the ranges $\lambda_{m}=45^{\circ}-65^{\circ}$ and MLT $=3: 00-7: 00$. Data at these magnetic locations are divided into two-dimensional ranges of $5^{\circ}$ in latitude and one hour in 

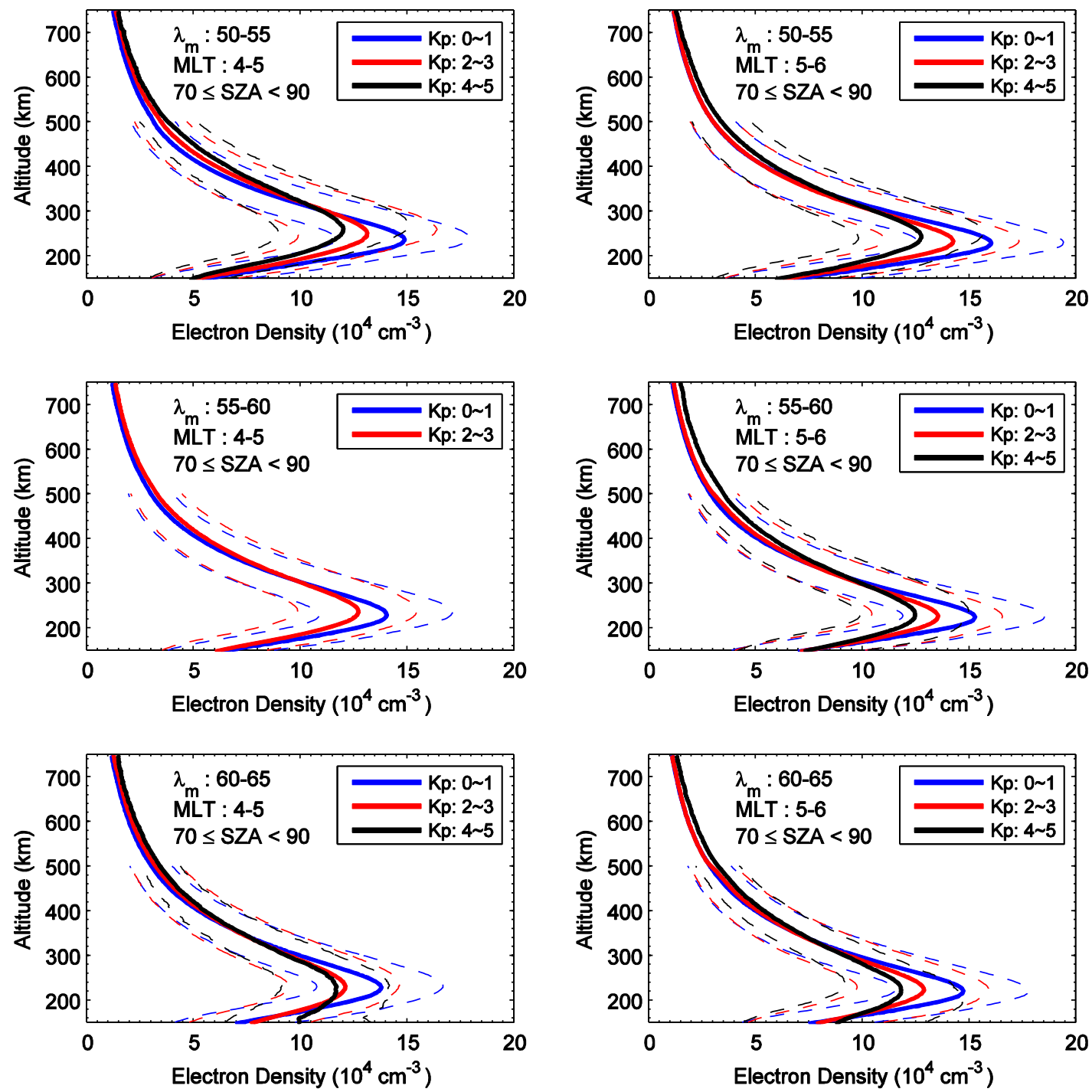

Fig. 2. Solid lines: average EDPs with $70^{\circ} \leq \mathrm{SZA}<90^{\circ}$ observed at the various $\lambda_{m}$ and MLT locations, appropriate for the three $K p$ ranges; dashed lines: color-coded plots for values at one standard deviation away from the average EDPs of the corresponding $K p$ ranges.

MLT. The third sorting criterion is the solar zenith angle (SZA) associated with the local ionosphere. Here, SZA is approximated as the angle subtended at the center of the Earth by the Sun and the local ionosphere because the Sun-Earth distance is much longer than the geocentric distance of the ionosphere. We consider three distinct SZA ranges: (1) $70^{\circ} \leq \mathrm{SZA}<90^{\circ}$ (sunlit ionosphere); (2) $90^{\circ} \leq \mathrm{SZA}<110^{\circ}$ (transition); (3) $110^{\circ} \leq \mathrm{SZA}<140^{\circ}$ (darkened ionosphere). The fourth sorting parameter relates to levels of geomagnetic activity indicated by the $K p$ index at times of observations. $K p$ values are divided into three ranges: $0-1$ for quiet conditions, 2-3 for weak disturbances, and 4-5 for strong disturbances (Bell, 1985). EDPs are divided into groups according to these four sorting criteria; each group distinctly features one of the 144 possible combinations of the ranges in $\lambda_{m}$, MLT, SZA and $K p$. Figure 1 indicates by color the numbers of profiles that satisfy the criteria of the data groups. Groups with 30 or fewer profiles are marked in white and were not considered in this statistical study. For each of the groups with more than 30 EDPs, an average density profile was determined based on the mean value of the EDPs obtained at each altitude. Effects of geomagnetic disturbances are established by comparing averaged EDP differences, in the same $\lambda_{m}$, MLT and SZA ranges, with different $K p$ values. As expected, many more EDPs are available with $K p$ in the $0-1$ and $2-3$ groupings than 4-5 within the same $\lambda_{m}$, MLT and SZA ranges. Thus, the data groups have a sufficient number of EDPs to support this statistical study.

Figure 2 shows the average density profiles along with the values at one standard deviation away for the three ranges of $K p$ when SZA was between $70^{\circ}$ and $90^{\circ}$, each panel corresponding to a data group within $\lambda_{m}=50^{\circ}-65^{\circ}$ and MLT $=4: 00-6: 00$ under the sunlit, post-dawn conditions. In the two-dimensional range of $\lambda_{m}=60^{\circ}-65^{\circ}$ and MLT $=4-5$ (bottom left panel), the average density at around $150 \mathrm{~km}$ altitude increases with $K p$. There is also a density increase with $K p$ at these altitudes at 5-6 MLT in the same latitudinal range (bottom right panel), but the perturbation effect is smaller. At $\lambda_{m}=50^{\circ}-55^{\circ}$ and $55^{\circ}-60^{\circ}$, such a density increase is not found in our statistical results. At altitudes higher than $200 \mathrm{~km}$, 

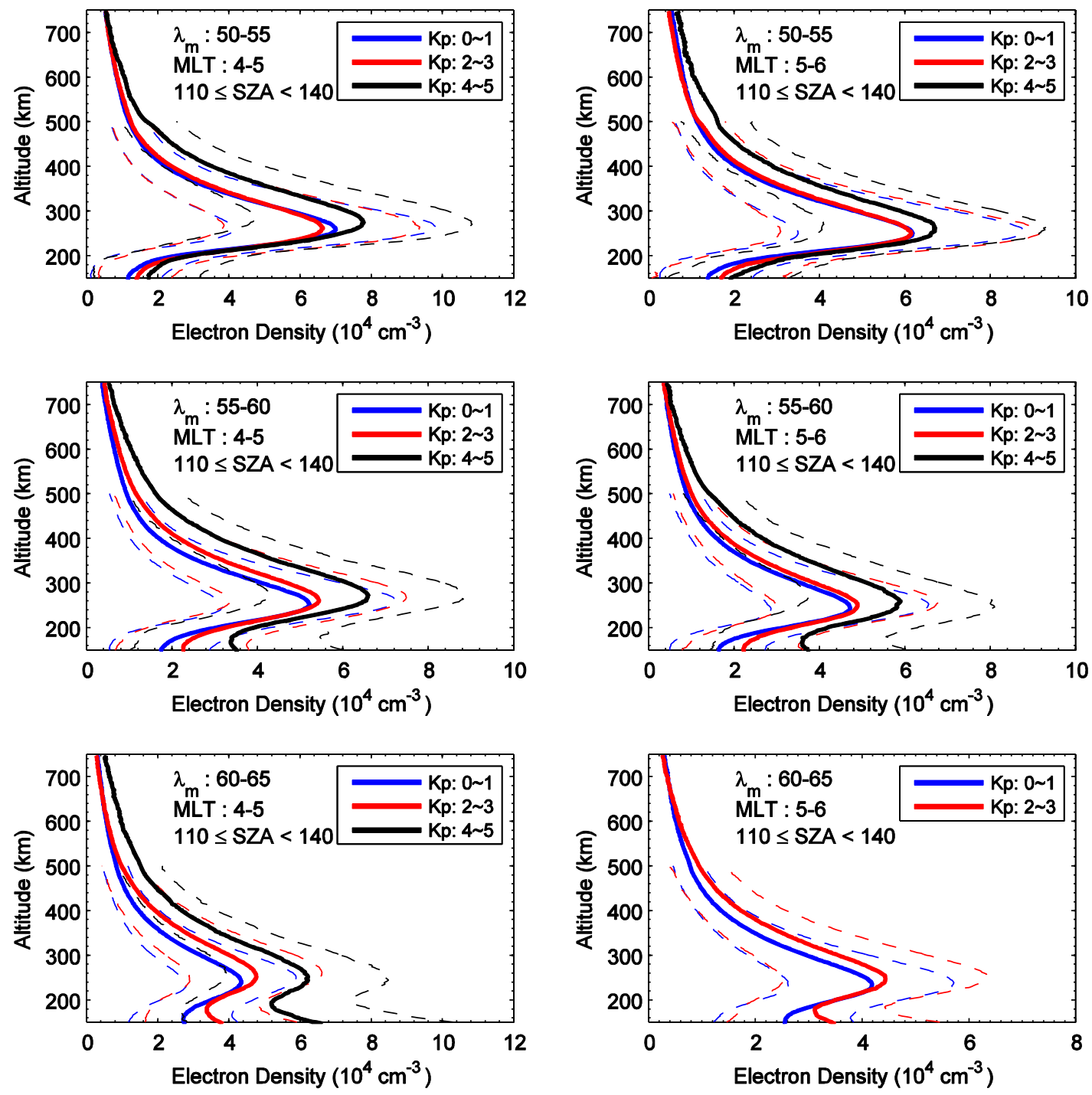

Fig. 3. Average EDPs with $110^{\circ} \leq \mathrm{SZA}<140^{\circ}$ along with the values at one standard deviation away, plotted in the same format as Figure 2 . The $K p=4-5$ plot is missing from the bottom right panel because of having $<30$ profiles.

corresponding to the F2 layer, it is clear that as $\mathrm{Kp}$ increases, the density decreases at each magnetic location considered in Figure 2.

Average density profiles at the same magnetic locations as in Figure 2 but with $110^{\circ} \leq \mathrm{SZA}<140^{\circ}$, corresponding to dark, pre-dawn conditions, are shown in Figure 3. Similar to the sunlit cases, there is a significant density increase at around $150 \mathrm{~km}$ altitude at $\lambda_{m}=60^{\circ}-65^{\circ}$ in the darkened ionosphere when $K p$ increases to 4 or 5 (bottom left panel of Fig. 3 ). In the lower latitudinal range of $\lambda_{m}=55^{\circ}-60^{\circ}$, in contrast to the corresponding magnetic locations under sunlit conditions, the plasma density at around $150 \mathrm{~km}$ altitude increases considerably as well during higher levels of geomagnetic activity for the pre-dawn cases (middle row of Fig. 3). At further lower latitudes where $\lambda_{m}=50^{\circ}-55^{\circ}$, the corresponding density increase also exists for the darkened ionosphere, but to a much lesser extent (top row of Fig. 3). At heights above $200 \mathrm{~km}$, geomagnetic activity produces a qualitative difference between the density perturbations in the sunlit and darkened ionosphere. In the pre-dawn cases (Fig. 3), the density increases significantly when geomagnetic disturbances elevate the $K p$ to levels of 4 or 5 . This trend in variations due to geomagnetic activity is clearly opposite to that found in the sunlit ionosphere at F2 altitudes (Fig. 2).

The average EDPs for $90^{\circ} \leq \mathrm{SZA}<110^{\circ}$ (night to day transition) are shown in Figure 4. These data feature locations that are partially sunlit to different extents. For instance, SZA's of $100^{\circ}, 105^{\circ}$ and $110^{\circ}$ correspond to local ionosphere that receives no direct sunlight below 98, 224 and $408 \mathrm{~km}$ altitudes respectively. Similar to the pre-dawn cases, there is an increase in the average density at around $150 \mathrm{~km}$ altitude in the latitudinal range of $60^{\circ}-65^{\circ}$ when geomagnetic activity is present (bottom panels). At $\lambda_{m}=55^{\circ}-60^{\circ}$, the density increases at these relatively low altitudes at 4-5 MLT (middle left panel) but the increase diminishes at 5-6 MLT (middle right panel). In the latitudinal range of $50^{\circ}-55^{\circ}$, the corresponding density increase seems even less significant (top panels). At altitudes $>200 \mathrm{~km}$, near the F-layer density peak, Figure 4 shows that perturbations due to geomagnetic activity may increase or decrease the density depending on locations. For example, 

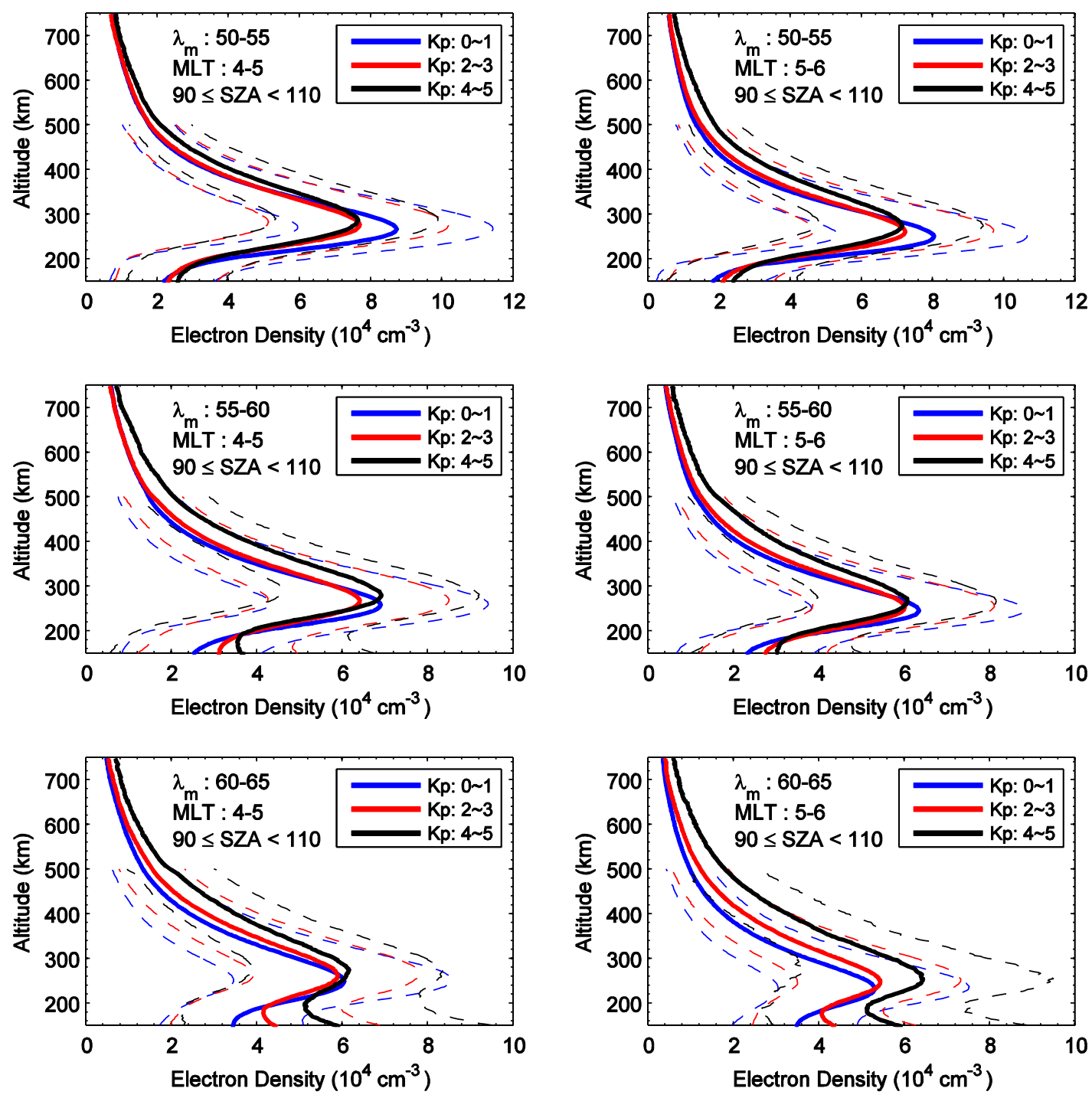

Fig. 4. Average EDPs with $90^{\circ} \leq \mathrm{SZA}<110^{\circ}$ along with the values at one standard deviation away, plotted in the same format as Figure 2 .

peak values of the average EDPs are larger for $K p$ levels 4-5 than corresponding values for $K p$ of $0-1$ at $\lambda_{m}=60^{\circ}-65^{\circ}$ (bottom panels), and at $\lambda_{m}=55^{\circ}-60^{\circ}$, MLT $=4-5$ (middle left panel). Peak densities change in the opposite way at $\lambda_{m}=50^{\circ}$ $55^{\circ}$ (top panels) and at $55^{\circ}-60^{\circ}$, MLT $=5-6$ (middle right panel), featuring smaller values at the higher $K p$ levels. For each set of magnetic locations shown in Figures 2, 3 and 4, we notice that in the transition region $90^{\circ} \leq \mathrm{SZA}<110^{\circ}$, effects due to geomagnetic disturbances on the peak density, whether positive or negative, are relatively small in comparison with those observed in the sunlit or darkened ionosphere. In panels of Figure 4 that indicate decreases in peak densities associated with stronger geomagnetic activity, the negative effects are more prominent in the corresponding sunlit regions (Fig. 2). Similarly, positive peak density effects that are shown in Figure 4 appear much less significant when compared with those seen in the corresponding regions under darkened ionospheric conditions (Fig. 3).

Table 1 summaries the electron densities at $150 \mathrm{~km}$ and the peak electron densities in the $\mathrm{F} 2$ region for all the cases in
Figures 2, 3 and 4. Overall, these cases feature the following common trends at around $150 \mathrm{~km}$ altitude for all three SZA ranges: the density increases at $\lambda_{m}=60^{\circ}-65^{\circ}$ when $K p$ is larger (bottom panels), but this positive density perturbation is less and less significant as $\lambda_{m}$ decreases to $55^{\circ}-60^{\circ}$ (middle panels) and further to $50^{\circ}-55^{\circ}$ (top panels). In fact, as shown in the top and middle panels of Figure 2, this positive effect on the density is not statistically significant at $\lambda_{m}<60^{\circ}$ for the sunlit ionosphere, as the densities at around $150 \mathrm{~km}$ altitude are not sensitive to the change in $K p$. For the darkened ionosphere, however, this perturbation effect may increase the density considerably at latitudes as low as $55^{\circ}-60^{\circ}$ (Fig. 3).

The positive density perturbation discussed above is likely due to particle precipitation when the equatorward edge of the auroral oval shifts to lower latitudes during periods of strong geomagnetic activity (Makita et al., 1983; Hardy et al., 2008). One expects this mechanism most often to affect the relatively high subauroral latitudes of $60^{\circ}-65^{\circ}$, which is just equatorward of the quiet-time auroral oval. As it would take stronger disturbances, which are less frequent to occur, for the auroral 
Table 1. Summary of electron densities at $150 \mathrm{~km}$ altitude and peak electron densities in the F2 region for the cases in Figures 2,3 and $4^{\text {a }}$.

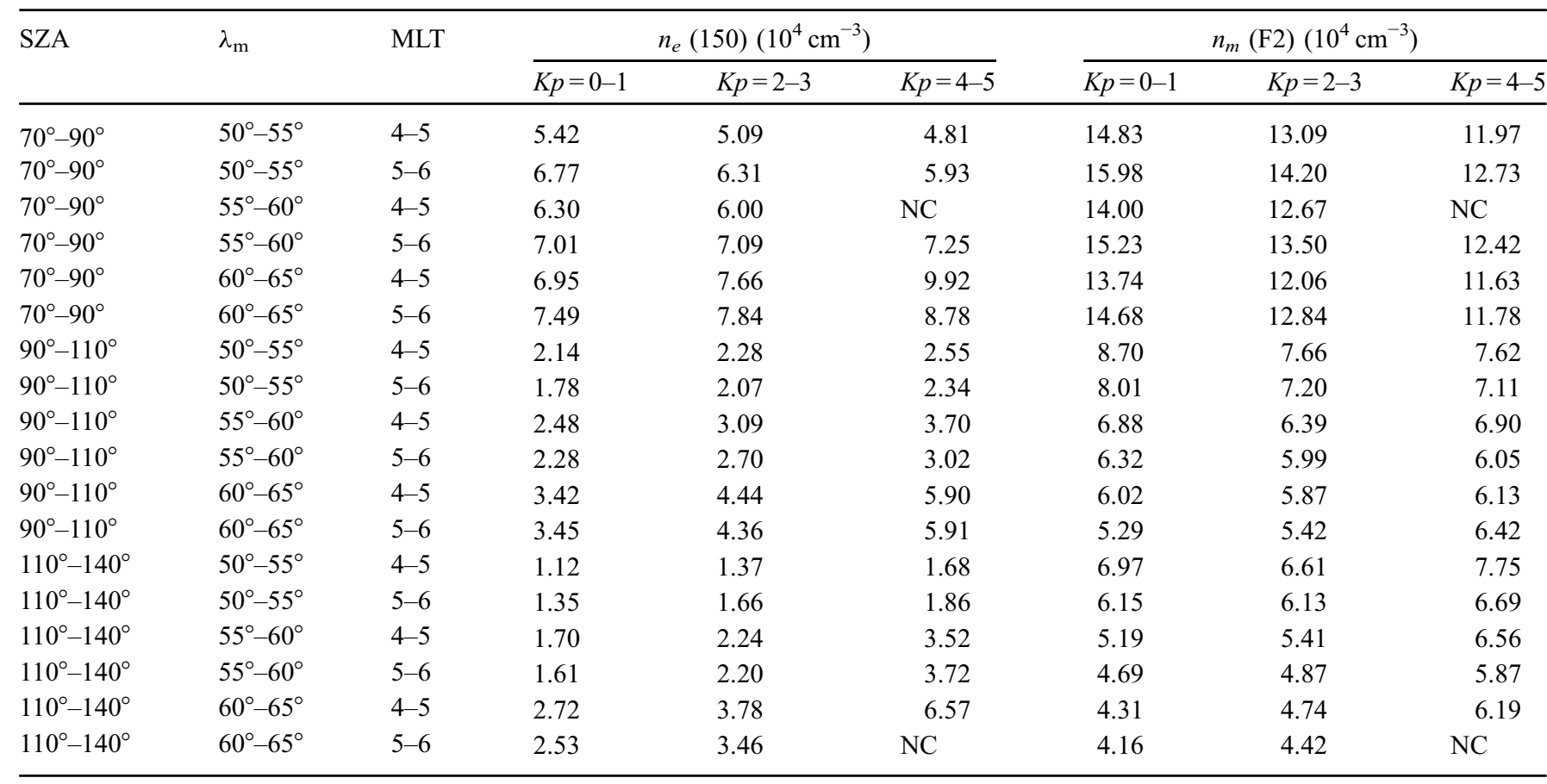

${ }^{\mathrm{a}} \mathrm{SZA}$ : solar zenith angle; $\lambda_{m}$ : magnetic latitude; MLT: magnetic local time; $n_{e}(150)$ : electron density at $150 \mathrm{~km}$ altitude; $n_{m}(\mathrm{~F} 2)$ : peak electron density in the F2 region; NC: not considered because the data group consists of $\leq 30$ electron density profiles.

oval to expand to lower latitudes, equatorward shifts of the particle precipitation region also explain why the positive effect on the density diminishes as $\lambda_{m}$ decreases. Based on the observations, particle precipitation as a contributing mechanism during disturbed times thus appears to be limited to subauroral latitudes of $60^{\circ}$ or above in the post-dawn ionosphere, while such an effect may extend to as low as $55^{\circ}$ in the pre-dawn sector.

For the F2 layer including $\mathrm{NmF} 2$, our statistical results show that in the ranges of $50^{\circ}-65^{\circ}$ latitude and 4-6 MLT, EDPs tend to increase before dawn but decrease afterwards during periods of high geomagnetic activity. Based on the results in Table 1, the average peak electron density in these ranges of $\lambda_{m}$ and MLT may increase by up to $44 \%$ in the darkened ionosphere (SZA $110^{\circ}-140^{\circ}, \lambda_{m}=60^{\circ}-65^{\circ}$ and MLT 4-5) and decrease by up to $20 \%$ in the sunlit ionosphere (SZA $70^{\circ}-90^{\circ}$, $\lambda_{m}=50^{\circ}-55^{\circ}$ and MLT 5-6) as $K p$ changes from 0-1 to 4-5. Density perturbations across the night-to-day transition range are between the two. These density-perturbation properties hold almost across our entire latitude-MLT ranges, as indicated in Figure 5. The only exception occurs in the predawn case (right panel) at $\lambda_{m}=45^{\circ}-50^{\circ}$, where the peak densities at MLT 3-4 and 4-5 are smaller at $K p$ levels of 4-5 than at $0-1$ by $\sim 2 \%$ and $12 \%$ respectively.

Statistical results presented above were obtained by calculating average densities at given altitudes. In principle, the reported effects could be misleading if the averages were dominated by a small fraction of the data measured during extreme density enhancement events. To test for such an error, we also calculated median densities at each altitude. These analyses indicate that averages and the medians yield similar qualitative density perturbations due to geomagnetic activity.
Thus, this statistical study has identified SZA to be an important factor related to the density perturbations at the subauroral and medium magnetic latitudes near the dawn terminator. From a space-weather perspective, these statistical observations may serve as an indicator of how the dawn-sector ionosphere at $65^{\circ}>\lambda_{m}>50^{\circ}$ will probably respond during similar geomagnetic disturbances: EDPs in pre-dawn/post-dawn ionosphere are dominated by positive/negative perturbations.

\section{Data analysis and identification of dominant mechanisms for density perturbation}

\subsection{Possible role of penetration electric fields}

An important objective of this study is to identify dominant mechanisms responsible for the observed positive and negative density perturbation effects particularly in the $\mathrm{F} 2$ region, where the perturbations are clearly dependent on the SZA. In this section, discussion will be focused only on the $\mathrm{F} 2$ region as we attempt to understand the physical reasons for the apparent association between SZA and density perturbations. The SZAdependence illustrated above suggests that the positive and negative plasma-density effects seen across the dawn terminator, if they are local in nature, are likely due to different mechanisms. However, it is possible for non-local mechanisms to cause both of the opposite effects on density. To first order we expect that in the absence of geomagneticactivity driving, plasma densities should systematically decrease between local midnight and dawn because of recombination. Thereafter they should increase in response 

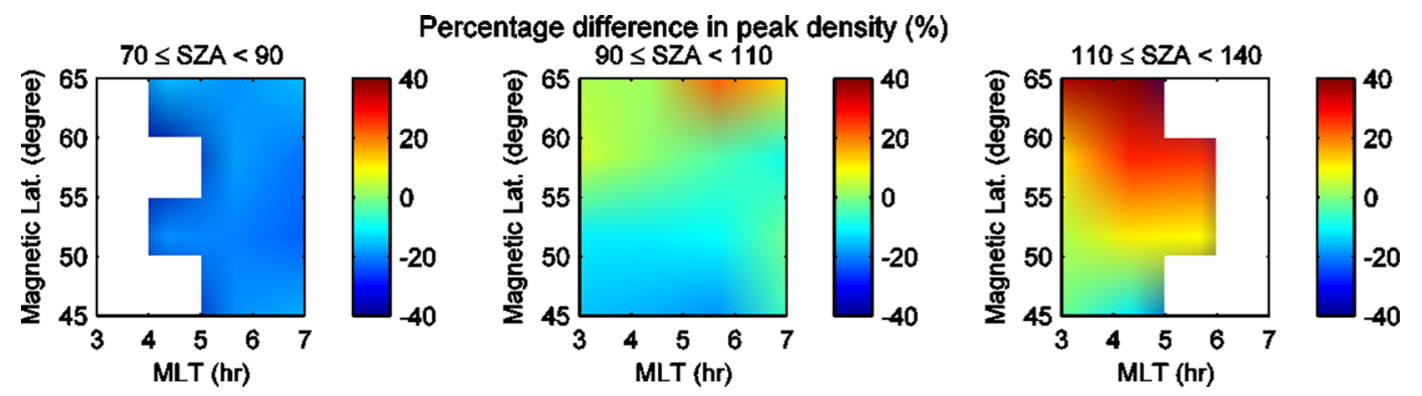

Fig. 5. Color plots of the percentage changes in the peak density of the average EDP at various magnetic locations when $K p$ increases from the range $0-1$ to $4-5$. Positive (negative) percentage differences correspond to an increase (decrease) in the peak density. White color is used when in either or both of the $K p$ ranges, there are 30 or fewer profiles observed at the specific magnetic location with the specific SZA value.

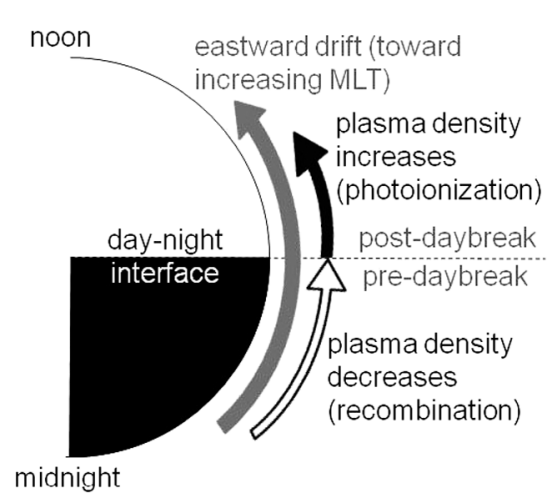

Fig. 6. Illustration of the direction of an eastward plasma drift (gray arrow) during the pre-daybreak and post-daybreak hours, which is toward increasing MLT, and the density variation of the corotating plasma due to the dominant effects of recombination before daybreak (empty arrow) and photoionization after daybreak (black arrow).

to sunlight-induced photoionization. Thus, there is expected to be a negative (positive) plasma density gradient in MLT before (after) dawn during quiet times. Interestingly, our reported F3C measurements show that the local density increases before (decreases after) dawn during periods of high geomagnetic activity, featuring changes that would be opposite to the quiettime density gradient in MLT. That is to say, for a local region, the effects of geomagnetic activity are consistent with its plasma being displaced by those from earlier MLT, which corresponds to an enhanced eastward drift of the corotating plasma in the presence of the quiet-time density gradients in MLT. Under an enhanced eastward plasma drift, the density at the pre-daybreak ionosphere would change to the level at an earlier local time, which is expectedly higher as illustrated in Figure 6. For regions well past daybreak, the densities at earlier local times are lower, meaning that an enhanced eastward plasma drift could only decrease the local density in those postdaybreak regions. For the partially sunlit region, the plasma densities at earlier local times, in principle, could be lower or higher; but the more sunlight a local ionosphere receives, the more likely an enhanced eastward drift would cause a negative effect on its density. Hence, eastward plasma drifts enhanced by high geomagnetic activity could be a reasonable explanation for our statistical observations in the three SZA ranges.
Eastward plasma drifts in the F-region ionosphere between the post-midnight and post-dawn locations during geomagnetically non-quiet times have been associated with convection due to the enhancement of the penetration electric fields (Wand $\&$ Evans, 1981a). It has long been realized that the mapping of the magnetospheric electric fields to the ionosphere, which occurs at latitudes above the Region-2 field-aligned currents, can penetrate to lower latitudes during disturbed times (Stern, 1979; and references therein). Wand \& Evans (1981b) used the F-region observations at Millstone Hill $\left(\lambda_{m} \approx 56^{\circ}\right)$ over a 19 month period to develop a local electric field model that depended on the local time, the day of the year, and the $K p$ index. They found that as the $K p$ index increased, the electric fields deviated more from their corresponding quiet-time $(K p=0)$ values at almost all local times. Such deviations, termed incremental electric fields, featured southward and westward components around the dawn hours. Based on the direction of $\mathbf{E} \times \mathbf{B}$, the southward component of the incremental electric fields would enhance the eastward drift velocity of the charged particles, providing the mechanism that may explain the density perturbations found for the three SZA ranges.

Meanwhile, the westward component of the incremental electric fields, because of the inclination of the geomagnetic field in the northern hemisphere, would enhance the drift velocity of the charged particles in the southward (equatorward) and downward directions. If we let $\Delta E_{\text {west }}$ be the westward incremental electric field component, the increase in the downward drift velocity would be:

$$
\Delta V_{E, \text { down }}=\Delta E_{\text {west }}(\cos I) / B
$$

where $B$ is the magnitude of the local magnetic field and $I$ is the magnetic inclination. Thus, the height of the plasma is affected by this incremental electric field component. However, geomagnetic activity also triggers neutral winds at subauroral latitudes (Emmert et al., 2004) - particularly anticipated in the events of auroral particle precipitation - affecting the plasma height as well. In this study, the EDPs with $K p$ values of 4 and 5 were likely under the influence of these triggered neutral winds, as typically more than $95 \%$ of the profiles in each of the data groups with these $K p$ values was associated with $\mathrm{AE}$ index of above $100 \mathrm{nT}$ at the minute of the observation, and more than $80 \%$ with $\mathrm{AE}>200 \mathrm{nT}$. Because the $\mathrm{AE}$ index characterizes the amount and strength of auroral activity and $\mathrm{AE}>100$ $\mathrm{nT}$ is commonly recognized as the condition for non-quiet 
times, it is reasonable to assume the presence of auroras at the time corresponding to the data that were associated with strong disturbances. In fact, as discussed earlier, auroral particle precipitation is indicated in the statistical results, particularly in the range of $\lambda_{m}=60^{\circ}-65^{\circ}$, suggesting that the presence of neutral winds, which can be generated as a result of Joule heating by the particle precipitation, was highly probable. These neutral winds at the subauroral latitudes would be equatorward, their momentum pushing the plasma upward along the field lines toward lower latitudes. This neutral windplasma interaction thus perturbs the plasma velocity in the upward direction while adding to the equatorward velocity component that may be enhanced at the same time by the penetration electric fields. If geomagnetic activity enhances the equatorward neutral wind by a horizontal velocity $\Delta \mathbf{U}_{\text {wind }}$, the upward velocity component of the plasma will accordingly increase by:

$$
\Delta V_{\text {wind,up }}=\Delta U_{\text {wind }} \sin I \cos I
$$

At $250 \mathrm{~km}$ altitude directly above Millstone Hill, for instance, where $B=47000 \mathrm{nT}$ and $I=71.36^{\circ}$ under a dipole field configuration, $\Delta E_{\text {west }}$ of $2 \mathrm{mV} / \mathrm{m}$ and $\Delta U_{\text {wind }}$ of $45 \mathrm{~m} / \mathrm{s}-$ both being realistic values according to Wand \& Evans (1981b) and Emmert et al. (2004) - will make $\Delta V_{E \text {,down }}$ and $\Delta V_{\text {wind,up }}$ virtually offset each other, giving perturbed velocity values of $13.67 \mathrm{~m} / \mathrm{s}$ and $13.63 \mathrm{~m} / \mathrm{s}$, respectively, based on equations (1) and (2). Thus, the net perturbed velocity of the plasma in the vertical direction could be small from a statistical perspective.

Hence, around the dawn hours, the statistically significant components of the perturbed plasma velocity due to penetration electric fields and equatorward neutral winds are expected to be eastward and equatorward, with the eastward component primarily attributed to the electric fields. It is reasonable to assume that the local plasma densities around the dawn ionosphere are more sensitive to the perturbed eastward motion because the density variation is intrinsically more prominent in the east-west direction as a result of the accumulating effects of recombination and photoionization on the corotating plasma (see Fig. 6). Thus, further data analyses are performed in this study to examine whether there is consistency between the statistical results and enhanced eastward electron drifts, the latter presumably due to incremental penetration electric fields associated with geomagnetic activity.

Enhanced eastward electron drifts correspond to the situation where electrons travel eastward at a faster speed than they do at quiet times. To understand how this change might affect the electron or plasma density in the ionosphere at a given MLT, consider a location at a particular latitude where, hypothetically, penetration electric fields are absent under the geomagnetically quiet conditions; the only quiet-time electric field present in the ionosphere at that latitude would be the one associated with corotation, which also corresponds to an eastward drift motion of the plasma. If one neglects the difference between MLT and local time at middle latitudes for the sake of argument, under quiet conditions, the plasma at the 0 hour MLT (midnight), for instance, would require three hours to reach the ionosphere at 3:00 MLT, during this period its density changing as a result of collisions, in particular, recombination. With the assumption that the local neutral density profile is similar along the path traversed by the plasma, the quiet-time plasma density profile at 3:00 MLT then reflects what becomes of the plasma at midnight after its charged particles undergo three hours of collisions among themselves and with the neutrals. Now consider the situation during disturbed times, where, in addition to the corotation electric field, a penetration electric field is present, increasing the eastward drift velocity of the plasma. If all other conditions are similar regardless of the level of geomagnetic activity, the plasma originally at the 0 hour MLT would undergo the same collision processes; its density profile as a function of elapsed time is expected to be similar to that during quiet times. However, its location after three hours would be eastward of 3:00 MLT, in other words, at a later MLT, say 4:00, as a result of the enhanced eastward drift velocity. Under these circumstances, comparing the density profiles during disturbed times against those during quiet times to obtain the local density perturbations at 4:00 MLT - the approach used in Section 2would be like comparing the quiet-time profiles at 3:00 MLT against the quiet-time profiles at 4:00 MLT; in other words, using the quiet-time profiles at 3:00 MLT to represent the disturbed-time profiles at 4:00 MLT. Overall, under the hypothesis that the incremental penetration electric field is the dominant mechanism affecting the subauroral ionosphere around the dawn hours during periods of geomagnetic disturbances, the density perturbations for a given location would be qualitatively similar to how the density at earlier MLT compares with the density at that location during quiet times.

\subsection{Method of analysis}

Based on the above idea of quiet-time plasma comparison, additional data analyses are performed for each range of $\lambda_{m}$ to examine whether enhanced eastward electron drifts could be the primary reason for the density perturbations observed during disturbed times. A positive result would indicate that the observations are consistent with the situation where the incremental penetration electric fields associated with geomagnetic activity are statistically the dominant mechanism for changing the local plasma density. As these additional data analyses are performed separately for each latitudinal range, they can reveal the ranges of $\lambda_{m}$ that correspond to such a situation, thereby providing an indication for the lowest latitudes that the electric fields can often penetrate during disturbed times. In fact, even when the primary reason for the density perturbation is not due to enhanced eastward electron drifts, the results of these analyses are still useful for the identification of the dominant mechanism(s) in each latitudinal range. Specifically, in these analyses, comparisons are made between quiet-time plasmas in adjacent MLT ranges at the same SZA and latitudes. Thus, for a given location, by setting its quiet-time $(K p 0-1)$ results as a standard to be compared against, we can use our approach in Section 2 together with the new approach of analysis to determine, respectively, the changes in the density-related properties upon: (I) an increase in $K p$; (II) a shift to an earlier MLT. If the two kinds of changes agree qualitatively, then the scenario is consistent with the incremental penetration electric field being the dominant factor affecting the density during disturbed times. Specifically, for 
the changes associated with (I), we use the results for $K p 4-5$ at the same location under the same SZA condition; for (II), we use the results for $K p 0-1$ in the same $\lambda_{m}$-range under the same SZA condition, but at MLT one hour earlier. The comparison between (I) and (II) focuses on two properties: in addition to the peak value of the average EDP, the mean hmF2 value among the data sets in the group is also examined. The percentage difference in the peak density shown in Figure 5, in principle, could be used as the results for (I). However, the averaging process to generate those results did not take into account the possible density difference due to the different seasons. If the seasonal composition of the data sets for data groups with the same SZA, MLT and $\lambda_{m}$ but different $K p$ ranges is very different, then the density perturbations obtained in Section 2 could be affected by the intrinsic density difference due to the seasonal effect. Although the seasonal composition among the groups that differ only in $K p$ does not vary significantly in the data set, we modify the procedure of finding averages as follows in order to eliminate the possibility of statistical bias caused by the seasonal effect: whenever two data groups are compared to find the changes associated with (I), the same set of weighting factors for the seasons is used to calculate the averages. The set of weighting factors to use is proportional to the numbers of EDPs for the seasons in the data group with $K p$ 4-5. For (II), the quiet-time data are divided according to seasons and calculations are performed for each season to eliminate the possible bias.

As mentioned earlier, changes due to (II) are examined based on comparisons between adjacent MLT ranges of the same SZA and latitude, even though in principle there are situations where the earlier MLT may belong to a larger SZA range; e.g. location at $6 \mathrm{MLT}$ with $90^{\circ}-110^{\circ} \mathrm{SZA}$ but location at 5 MLT of the same latitude with $110^{\circ}-140^{\circ} \mathrm{SZA}$. In the situation of the example, the comparison between 5 and 6 MLT is based on $90^{\circ}-110^{\circ} \mathrm{SZA}$ because the later MLT is the locality where enhanced eastward drifts are being examined for consistency with the observations. In fact, if we were to allow comparisons across SZA ranges, the results would be strongly influenced by the intrinsic density difference between different SZAs, which feature different photoionization rates. As we shall explain below, that would likely lead to an overestimation of the density difference if enhanced eastward drifts are indeed the dominant mechanism to change the density during disturbed times. Using the above example, we note that for the plasma to drift from 5 to 6 MLT, the SZA of its location decreases continuously. Although the plasma starts at $110^{\circ}-$ $140^{\circ} \mathrm{SZA}$ and thus probably has a rather low density compared with that at $6 \mathrm{MLT}$, it will enter the $90^{\circ}-110^{\circ} \mathrm{SZA}$ range at some point during its drift, along with an increase in density due to increased photoionization. By the time the plasma reaches 6 MLT, its density should be considerably larger than that at 5 MLT with $110^{\circ}-140^{\circ} \mathrm{SZA}$. Hence, by using the same SZA for the comparison $-90^{\circ}-110^{\circ}$ in the above example we avoid overestimating the density difference associated with (II).

Each of Figures 7-10 shows the results for the peak density and mean hmF2 in a $\lambda_{m}$-range, as well as how the changes due to (I) and (II) compare qualitatively. All of these figures have the same format that is described below. Panels (a) and (f), which are the larger panels, indicate the changes associated with (I), in terms of the percentage changes in the peak value of the average EDP and the changes in the mean hmF2 respectively. Results for different SZA ranges are plotted with different color groups: blue for $110^{\circ}-140^{\circ}$, green for $90^{\circ}-110^{\circ}$, and red for $70^{\circ}-90^{\circ}$. Within each group, the light color (i.e. light blue, light green, or pink) is used to indicate an increase in the quantity due to (I), and the dark-color version (dark blue, dark green, or red) to indicate a decrease. Panels (b)-(e) of each figure show the peak densities of the average EDPs in the four seasons during $K p$ values of $0-1$. The corresponding mean values of hmF2 in the four seasons are shown in Panels (g)-(j). The plots in those eight panels are color-coded to indicate the change associated with (II), as elaborated below. First, all the results in those panels are based on quiet-time $(K p 0-1)$ data at the specified combinations of SZA and MLT ranges during the season specified. There are results missing in the plots for certain combinations of SZA and MLT; those results are neglected in our study as they were based on the statistics of 30 or fewer available data profiles. For a given SZA-MLT combination, we can compare the quantity of interest with that in the same season in the same SZA range but with MLT one hour earlier to obtain the change associated with (II), provided that the values for both SZA-MLT combinations are available under the consideration of the above statistical criterion. If the data with the same SZA at MLT one hour earlier were either insufficient or not considered in this study, then uncolored symbols are used. Otherwise, the symbol at the given MLT will be filled with color to indicate the result of the comparison. The color scheme follows a principle similar to that for Panels (a) and (f): the color groups of blue, green and red are for SZA ranges of $110^{\circ}-140^{\circ}, 90^{\circ}-$ $110^{\circ}$ and $70^{\circ}-90^{\circ}$, respectively, with the light (dark) tones of the colors indicating an increase (decrease) in the plotted quantity due to (II). For instance, in Figure $7 \mathrm{~b}$, the square at MLT 4-5 is filled with light green because the peak density for the same SZA $\left(90^{\circ}-110^{\circ}\right)$ at one hour earlier (MLT 3-4) is higher, meaning that a change associated with (II) would cause an increase in the peak density at hour 4-5. As the large panels - (a) and (f) - are plotted with a similar color scheme - light color tones for increase and dark colors for decrease - that corresponds to the change associated with (I), one can examine whether the changes due to (I) and (II) are consistent by comparing the colors in the related panels. If the colors in Panels (b)-(e) match those at the corresponding MLT for the same SZA range in Panel (a), while the colors in Panels (g)-(j) also match the corresponding colors in Panel (f), then data at those latitude-MLT-SZA ranges are consistent with the idea of enhanced eastward convection being the primary mechanism for the density perturbations during disturbed times. Otherwise, there are probably other physical mechanisms more dominant than the incremental penetration electric field at those magnetic locations under the given SZA conditions.

\subsection{Interpretation of results and identification of dominant mechanisms}

\subsubsection{Magnetic latitudes: $60^{\circ}-65^{\circ}$}

The results at $\lambda_{m}=60^{\circ}-65^{\circ}$ are shown in Figure 7 , which features unmatched shades in all three colors. For the SZA ranges of $90^{\circ}-110^{\circ}$ and $110^{\circ}-140^{\circ}$, the discrepancies can be found in both the peak density and mean hmF2. At $70^{\circ}-90^{\circ}$ 


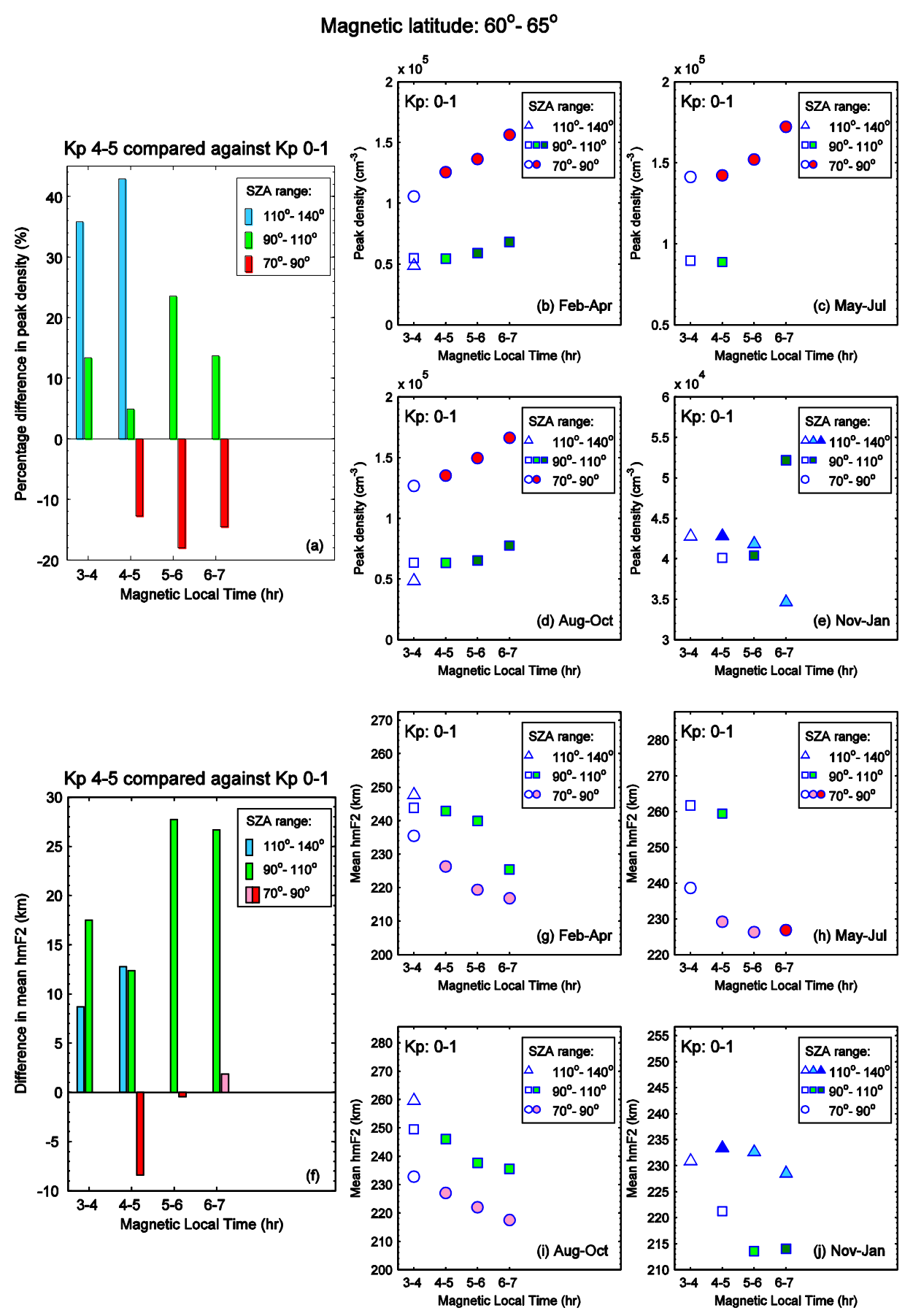

Fig. 7. Statistical observations at $60^{\circ}-65^{\circ}$ latitude: (a) plots of the percentage change in the peak density due to $K p$ increasing from the range $0-1$ to 4-5; (b)-(e) plots of the quiet-time peak density for different seasons; (f) plots of the change in the mean hmF2 due to $K p$ increasing from the range $0-1$ to $4-5 ;(\mathrm{g})-(\mathrm{j})$ plots of the quiet-time values of the mean hmF2 for different seasons. The plots are color-coded. See the text for details.

SZA, however, the disagreement is only in the mean hmF2. Specifically, at $110^{\circ}-140^{\circ} \mathrm{SZA}$, unmatched blue colors are found in the 4-5 MLT range from Panels (a) and (e) for the results involving the peak density. As shown in Panel (a), the peak density increases by more than $40 \%$ as a result of the enhanced geomagnetic activity; however, a mere eastward shift of the quiet-time plasma in November-January - the only season that has sufficient data for the comparison between MLT 3-4 and 4-5 under the darkened ionospheric condition - would result in a slight decrease at MLT 4-5 (Panel (e)). For the mean hmF2 in this SZA range, Panel (f) features an increase due to elevated $K p$ that is unaccounted for by an eastward shift of quiet-time plasma, as indicated by the symbol with an unmatched blue color at 4-5 MLT in Panel (j). At $90^{\circ}$ $110^{\circ} \mathrm{SZA}$, the changes in the peak density due to (I) and (II) are inconsistent in the MLT ranges of 5-6 and 6-7: Panel (a) indicates significant increase in both MLT ranges while Panels (b), (d) and (e) suggest that an eastward shift of the quiet-time 


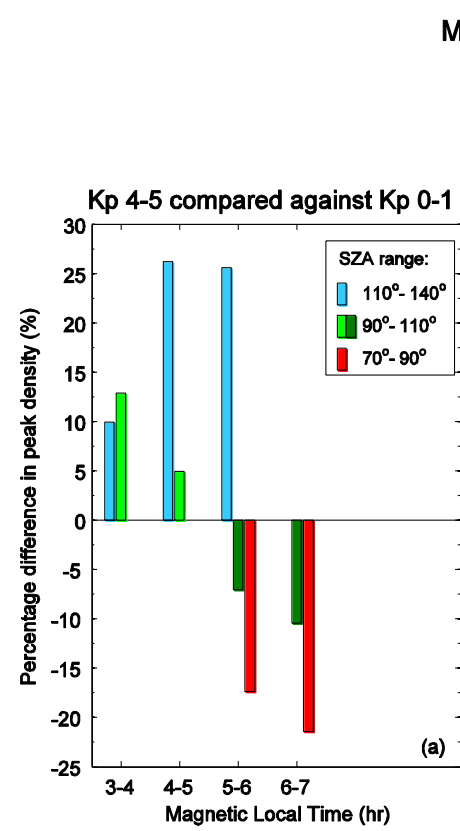

Magnetic latitude: $55^{\circ}-60^{\circ}$
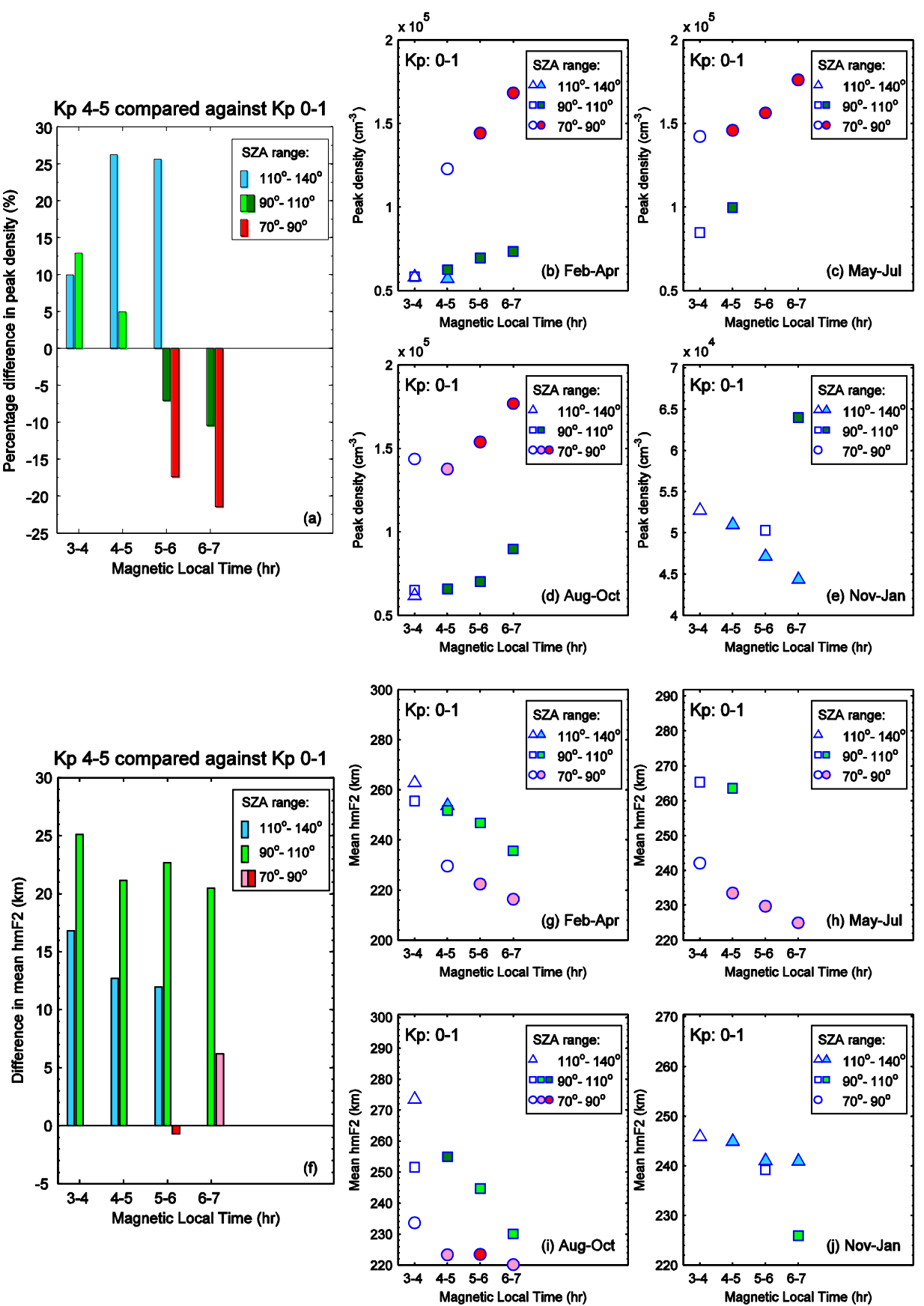

Fig. 8. Statistical observations at $55^{\circ}-60^{\circ}$ latitude. The meaning of the plots in the panels is the same as those in Figure 7 .

plasma would have an opposite effect. For the results of the mean $\mathrm{hmF} 2$ in this SZA range, the most noticeable feature in Panel (f) is the significant increase at all MLT. Specifically, when $K p$ increases from $0-1$ to $4-5$, the mean hmF2 increases by 12,28 , and $27 \mathrm{~km}$ in the $4-5,5-6$ and 6-7 MLT ranges respectively. Although there is only one unmatched color symbol overall for the mean hmF2 at $90^{\circ}-110^{\circ} \mathrm{SZA}$ in Figure 7 (MLT 6-7 in Panel (j)), the difference between the values in adjacent MLT ranges in Panels $(g)-(j)$ generally does not appear as large as what Panel (f) indicates. In fact, the average change associated with (II), combined over the seasons based on the weighting factors used to obtain the results in Panel (f), corresponds to increases of only 2,6 , and $2 \mathrm{~km}$ in the 4-5, 5-6 and 6-7 MLT ranges respectively, less than the corresponding increases due to (I) by $10-20 \mathrm{~km}$. At $70^{\circ}-90^{\circ} \mathrm{SZA}$, in contrast to the other two ranges, changes in the peak density associated with (I) and (II) are consistent at all MLT. Indications that an eastward plasma drift may not be the dominant mechanism in this SZA range during disturbed times come only from the results of the mean $\mathrm{hmF} 2$, in the form of unmatched red/pink colors between Panel (f) and Panels (g)-(i) of Figure 7 for the three MLT ranges between 4:00 and 7:00. Nevertheless, at 6-7 


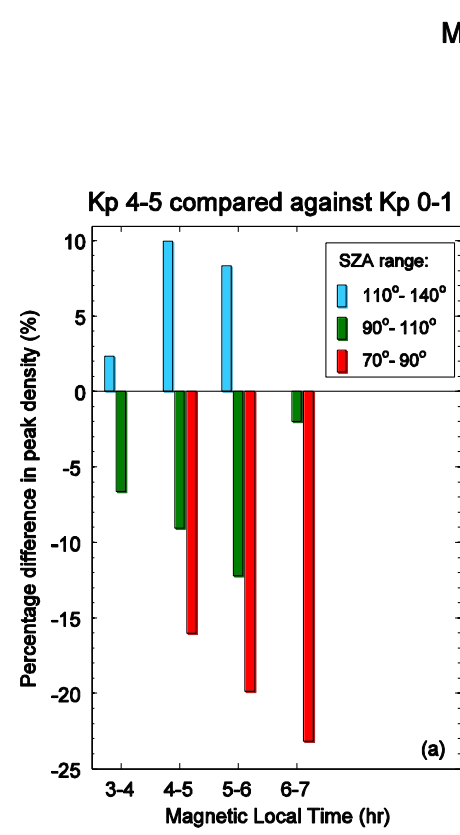

Magnetic latitude: $50^{\circ}-55^{\circ}$
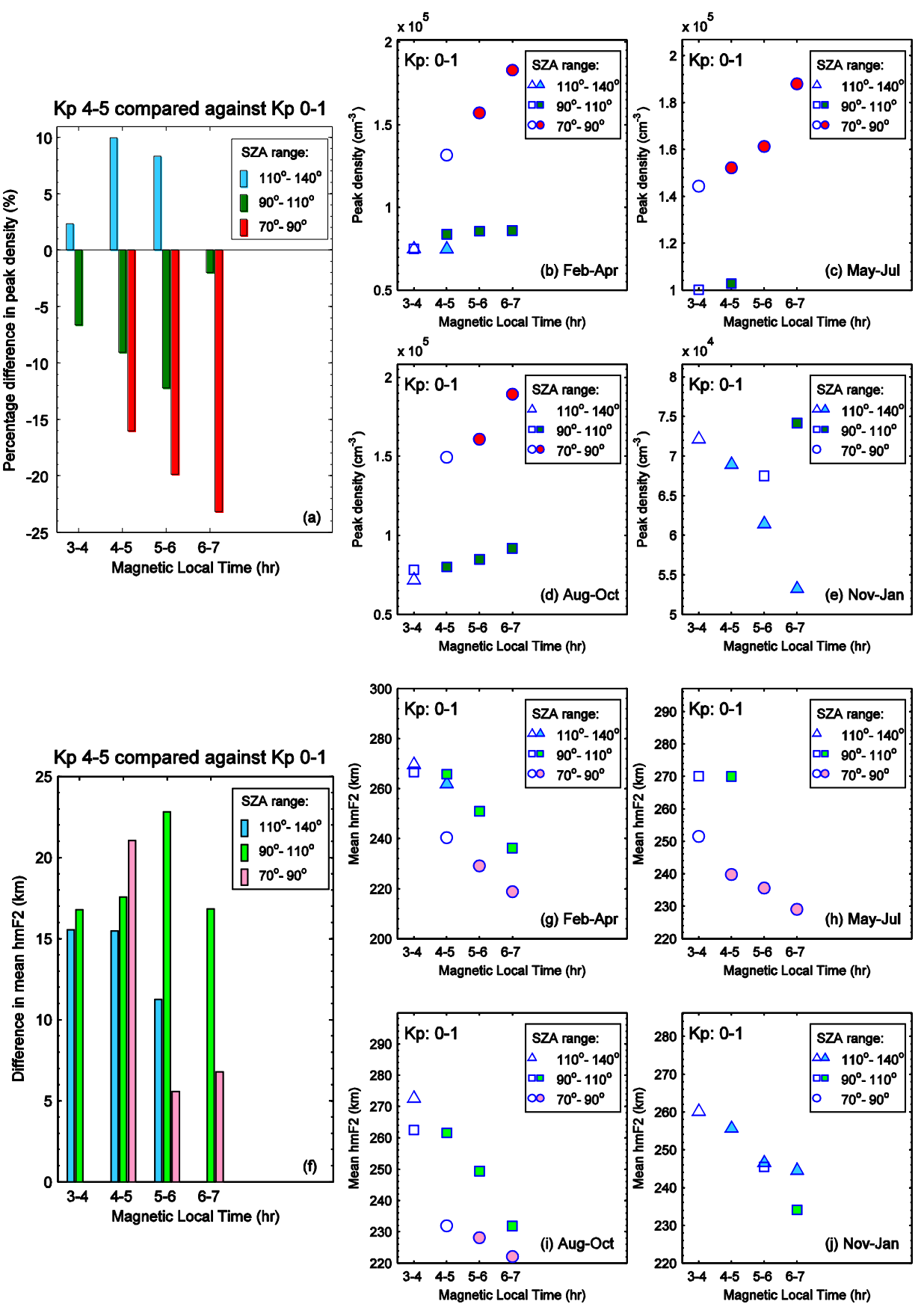

Fig. 9. Statistical observations at $50^{\circ}-55^{\circ}$ latitude. The meaning of the plots in the panels is the same as those in Figure 7 .

MLT, the inconsistency with the result in Panel (f), which is found only in the May-July season (Panel (h)) but not in February-April and August-October (Panels (g) and (i)), is minimal. In fact, if the weighting factors for the seasons are used to determine the average change associated with (II), the mean hmF2 would then increase by $3 \mathrm{~km}$, consistent with the corresponding result in Panel (f). Similar calculations for MLT 4-5 and 5-6 would find the mean hmF2 increase in association with (II) by about 8 and $6 \mathrm{~km}$ respectively, while the corresponding results due to (I), as shown in Figure $7 \mathrm{f}$, are decreases by 8 and $0.4 \mathrm{~km}$.
As significant inconsistency between changes due to (I) and (II) is found for both the peak density and the mean hmF2 at $90^{\circ}-110^{\circ}$ and $110^{\circ}-140^{\circ} \mathrm{SZA}$, one can conclude that the effect of incremental penetration electric fields does not dominate at $\lambda_{m}=60^{\circ}-65^{\circ}$ at these two SZA ranges. Instead, the primary mechanism for the density perturbations is likely due to particle precipitation, whose existence is indicated in the bottom panels of Figures 3 and 4 for the two SZA ranges by the large density increases at altitudes below $200 \mathrm{~km}$ when $K p$ increases. The effect of auroral electron precipitation on the ionosphere before sunrise has been investigated based on a 


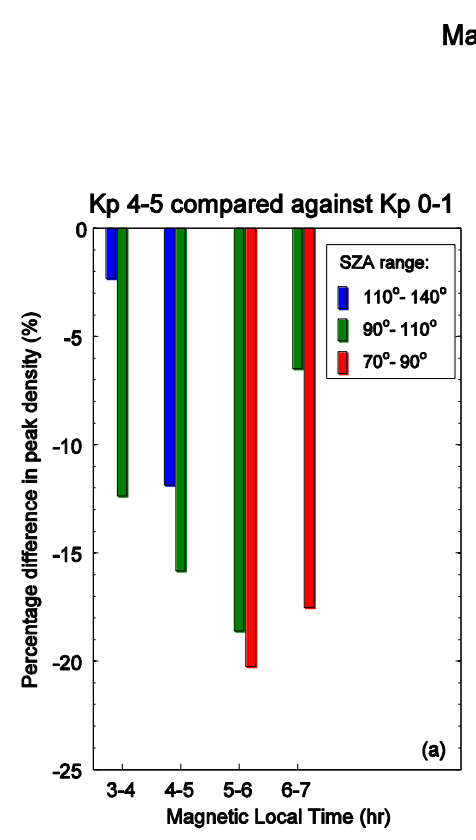

Magnetic latitude: $45^{\circ}-50^{\circ}$
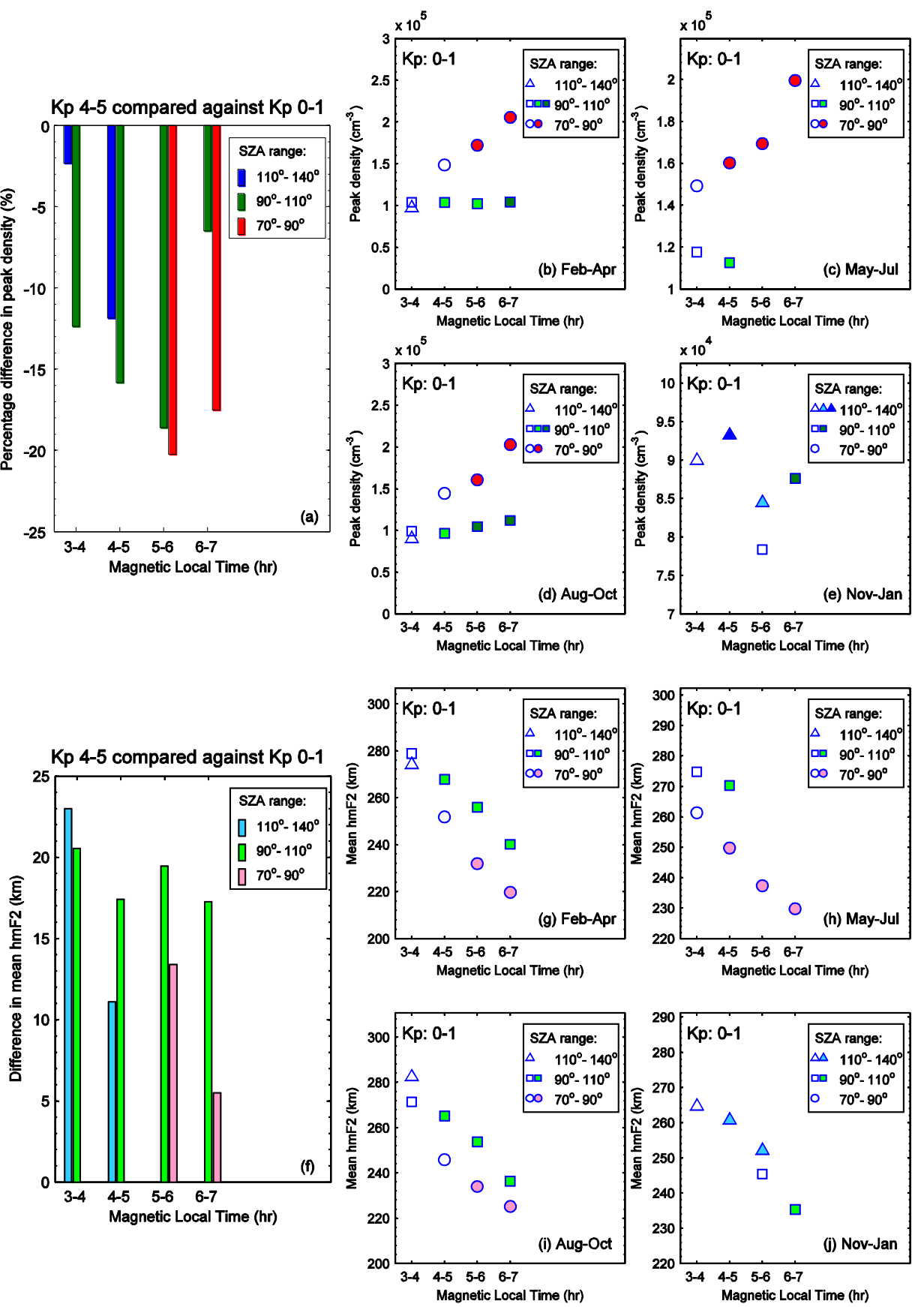

Fig. 10. Statistical observations at $45^{\circ}-50^{\circ}$ latitude. The meaning of the plots in the panels is the same as those in Figure 7 .

simulation by Richards (1995). The study showed that in association with an increase in the peak density, the hmF2 would increase immediately after the period of electron precipitation and would remain about 10 or $20 \mathrm{~km}$ higher than the normal values for a few hours. The observations for both the peak density and the mean $\mathrm{hmF} 2$ at $90^{\circ}-110^{\circ}$ and $110^{\circ}-140^{\circ} \mathrm{SZA}$, as shown in Panels (a) and (f) of Figure 7, agree with these simulation results with auroral electron precipitation.

For the $70^{\circ}-90^{\circ} \mathrm{SZA}$ range, however, the negative effect on the peak density as shown in Figure 7a suggests that the dominant mechanism is unlikely auroral electron precipitation. The matching of the red color in Panels (a)-(e) of Figure 7 indicates that the observations of the peak density are, instead, consistent with enhanced eastward electron drifts causing the density decrease observed during disturbed times, especially since the negative effect is, as discussed earlier, in agreement with the expectation of this mechanism in the post-daybreak ionosphere. For the mean hmF2, as discussed earlier, the averages based on the weighting factors for the seasons would render increases of 8 , 6 and $3 \mathrm{~km}$ respectively at MLT 4-5, 5-6 and 6-7 upon changes due to (II). Those values are to be compared with the corresponding results due to (I), changes of $-8,-0.4$ and 
$2 \mathrm{~km}$ respectively, as shown in Figure $7 \mathrm{f}$. Thus, enhanced eastward electron drifts cannot completely account for the changes in the mean $\mathrm{hmF} 2$ during disturbed times at 4-6 MLT. Nevertheless, because the estimated changes associated with (II) would render hmF2 higher than those with (I) while the amount of the discrepancy reduces as the MLT progresses, one may not immediately rule out the incremental penetration electric fields as the primary physical mechanism for the following reason. Note that the enhanced eastward drift is identified to be the main mechanism for the incremental penetration electric fields to change the ionospheric plasma density. However, the incremental penetration electric fields, as discussed earlier, also lead to a downward drift of the plasma, which is in association with the westward component of the fields. Although this drift may be offset by an upward drift caused by the neutral wind, it can be dominant especially when the perturbed electric fields are the primary mechanism for the density perturbation, which could be the case here as supported by the results regarding the peak density. Moreover, Figure 1 of Wand \& Evans (1981b) indicated that the westward component of the perturbed electric fields was the strongest at 4 am local time and reduced after that. Such a trend would correspond to a downward drift of the plasma with the drift velocity decreasing with the MLT after $4 \mathrm{am}$. As this effect translates to a change in altitude, it reduces the mean $\mathrm{hmF} 2$ in such a way that the decrease is to a lesser extent as the MLT progresses. Thus, the downward drift due to the perturbed electric fields may supplement the eastward drift associated with the fields to account for the aforementioned discrepancy in the mean $\mathrm{hmF} 2$ in the $70^{\circ}-90^{\circ}$ SZA range. Therefore, for the $60^{\circ}-65^{\circ}$ latitudinal range, the results of this study are consistent with the incremental penetration electric fields being the dominant density perturbation mechanism at $70^{\circ}-90^{\circ} \mathrm{SZA}$.

\subsubsection{Magnetic latitudes: $55^{\circ}-60^{\circ}$}

The results for the peak density and the mean $\mathrm{hmF} 2$ at $\lambda_{m}=$ $55^{\circ}-60^{\circ}$ are shown in Figure 8. From Panels (a) and (f), one can see that generally for the $110^{\circ}-140^{\circ}$ SZA range the peak density and the mean $\mathrm{hmF} 2$ both increase in association with (I). Those changes are qualitatively the same as the corresponding changes associated with (II), as indicated by the matching of the blue color throughout the figure. In the SZA range of $90^{\circ}-110^{\circ}$, the change in the peak density due to (I) features a positive effect at 3-5 MLT but a negative effect at 5-7 MLT (Fig. 8a), although the associated changes in the mean hmF2 are all positive for these MLT ranges (Fig. 8f). Upon checking whether these changes would be consistent with (II), we find matching dark green color at 5-7 MLT among Panels (a)-(e) and matching light green color among Panels (f)-(j). However, at 4-5 MLT, the corresponding green colors generally exhibit no such matching. For $70^{\circ}-90^{\circ}$ SZA in this latitudinal range, the changes in the peak density due to (I) and (II) are consistent, as indicated by the matching red color in Panels (a)-(e) of Figure 8. The corresponding changes in the mean hmF2 also agree at 6-7 MLT as the matching pink color in Panels (f)-(j) suggests. However, there is a discrepancy at 56 MLT: the change associated with (I) is negative although quite minimal, by only $0.7 \mathrm{~km}$ (Fig. $8 \mathrm{f}$ ), while the change due to (II) could vary by the season but overall appearing to incline toward a positive change (see Fig. 8g, 8h and 8i).
Consideration of the weighted average over the seasons would render an increase of about $4 \mathrm{~km}$ in the mean hmF2 of MLT 56 in association with (II).

At $110^{\circ}-140^{\circ} \mathrm{SZA}$, although all the changes due to (I) and (II) qualitatively agree - every change in the peak density and the mean $\mathrm{hmF} 2$ being an increase - the increase in the peak density shown in Figure 8a, specifically at 4-5 and 5-6 MLT, appears considerably larger than what an eastward shift of quiet-time plasma would give according to Panels (b) and (e) of the figure. Thus, the incremental penetration electric fields may not be the best interpretation for the density perturbation associated with geomagnetic activity. In fact, as one may recall from the discussion above, significant increase in both the peak density and the mean $\mathrm{hmF} 2$ can be resulted from auroral electron precipitation. By examining the middle panels of Figure 3, one can confirm that at $110^{\circ}-140^{\circ}$ SZA, 4-5 and 5-6 MLT in the $55^{\circ}-60^{\circ}$ latitudinal range, the average density profiles indeed feature significantly larger density below $200 \mathrm{~km}$ altitude when $K p$ elevates to 4-5, an indication of the effect of auroral electron precipitation.

In the SZA range of $90^{\circ}-110^{\circ}$, the consistency between changes due to (I) and (II) at 5-7 MLT suggests that incremental penetration electric fields can be the primary mechanism under these ionospheric conditions. On the other hand, the same cannot be said for MLT 4-5, as indicated by the generally unmatched green colors. However, one notices that the changes due to (I) at this hour of MLT have been a familiar one: increase in both the peak density (Fig. 8a) and the mean hmF2 (Fig. 8f), which has been interpreted as auroral electron precipitation at $\lambda_{m}=60^{\circ}-65^{\circ}$. From the middle left panel of Figure 4, one can see that the density below $200 \mathrm{~km}$ altitude is indeed considerably higher when $K p$ increases, supportive of the interpretation that auroral electron precipitation is the primary mechanism associated with geomagnetic activity affecting the ionosphere at $\lambda_{m}=55^{\circ}-60^{\circ}$, MLT $4-5$, and SZA $90^{\circ}-110^{\circ}$.

For $70^{\circ}-90^{\circ} \mathrm{SZA}$, the situation is in fact similar to that for the same SZA range at $\lambda_{m}=60^{\circ}-65^{\circ}$. In both latitudinal ranges, the changes in the peak density due to (I) and (II) are consistent, both being negative. The changes in the mean hmF2 due to (I) decrease by less and even turn into an increase as MLT progresses, while under the consideration of averages over the season, changes due to (II) feature hmF2 at higher altitudes but these discrepancies with (I) become smaller at later MLT, eventually with two results agreeing at 6-7 MLT. These similarities - consistent results between (I) and (II) for the change in the peak density but relatively negative change in the mean hmF2 for (I) compared with (II) - suggest that the physical mechanism to explain the results at $70^{\circ}-90^{\circ} \mathrm{SZA}$ for $\lambda_{m}=60^{\circ}-65^{\circ}$ should also be the dominant mechanism here. Therefore, for $\lambda_{m}=55^{\circ}-60^{\circ}$ as well, the incremental penetration electric fields can be interpreted as the dominant density perturbation mechanism at $70^{\circ}-90^{\circ}$ SZA.

\subsubsection{Magnetic latitudes: $50^{\circ}-55^{\circ}$}

The results for the peak density and the mean $\mathrm{hmF} 2$ at $\lambda_{m}=50^{\circ}-55^{\circ}$ are shown in Figure 9. Note that throughout the plots for the peak density, Panels (a)-(e), only one shade of color appears for each of the three SZA ranges: light blue for SZA of $110^{\circ}-140^{\circ}$, dark green for $90^{\circ}-110^{\circ}$, and red for $70^{\circ}-$ 
$90^{\circ}$. The percentage change in the peak density indicated in Panel (a) is also comparable with the corresponding values that Panels (b)-(e) may give. Similar agreement is also found between Panel (f) and Panels (g)-(j) for the results of the mean hmF2. Thus, the comparison between the changes associated with (I) and (II) suggests that enhanced eastward drifts of the plasma are probably the explanation for the observed statistical density perturbations during disturbed times.

This interpretation is further examined under the consideration whether the qualitative change in the peak density shown in Panel (a) is physically consistent with enhanced eastward plasma drifts, whose effects on the density have been briefly discussed in Section 3.1. Note that during the night time when there is no photoionization by the sunlight, the local electron density of the ionosphere is expected to decrease deeper into the night because of recombination. At the daynight interface, however, the local electron density begins to increase as photoionization takes place in the presence of sunlight. The electron density would keep increasing with the local time after dawn, as photoionization occurs faster than recombination and the photoionization rate increases as a result of the decrease in the SZA. According to the above variation pattern of the local electron density, one would expect an enhanced eastward drift of the plasma, which essentially changes the local ionosphere back to the conditions corresponding to an earlier time, to lead to an increase in the density for the darkened, pre-dawn ionosphere but a decrease in the density for a dawnside ionosphere that has already received sunlight for a considerable amount of time. Such a pattern is exactly what Figure 9a indicates for the peak density: increase at $110^{\circ}-140^{\circ} \mathrm{SZA}$ but decrease in the SZA ranges of $70^{\circ}-90^{\circ}$ and $90^{\circ}-110^{\circ}$. Therefore, the observed statistical results at $\lambda_{m}=50^{\circ}-55^{\circ}$ can be explained by enhanced eastward drifts of the plasma due to the incremental penetration electric fields.

\subsubsection{Magnetic latitudes: $45^{\circ}-50^{\circ}$}

The results for the peak density and the mean hmF2 at $\lambda_{m}=45^{\circ}-50^{\circ}$ are shown in Figure 10. Although the colors of the plots in Panels (f)-(j) indicate no disagreement in terms of the change in the mean hmF2 due to (I) and (II), the same is not true for the change in the peak density. Specifically, the green color, which corresponds to the SZA range of $90^{\circ}-110^{\circ}$, features only the darker shade in Panel (a), but the lighter shade is found for MLT 4-5 and 5-6 in Panel (b) and MLT 4-5 in Panels (c) and (d). Overall at 4-5 MLT for this particular range of SZA, the change in the peak density due to (II) would be an increase, in contrast to the negative effect indicated in Panel (a) for the corresponding change associated with (I).

At $110^{\circ}-140^{\circ} \mathrm{SZA}$, although there is no unmatched color for MLT 4-5, which is the only comparable MLT range for the blue color, the decrease in the peak density indicated in Figure 10a is inconsistent with the effect due to an enhanced eastward plasma drift. As discussed before, in this SZA range that corresponds to a darkened ionosphere, the density should increase as a result of such a drift. With consideration of this inconsistency along with the disagreement in the peak density change due to (I) and (II) at $90^{\circ}-110^{\circ} \mathrm{SZA}$, enhanced eastward plasma drifts cannot be the explanation for the observed density perturbation at $\lambda_{m}=45^{\circ}-50^{\circ}$.
In fact, back to a more fundamental point of view, we notice from Figure 10a and Figure 10f that the peak density decreases and the mean hmF2 increases in association with geomagnetic disturbances regardless of the MLT range or the SZA range. An increase in the plasma height is generally associated with an increase in the plasma density because the densities of neutral molecules such as $\mathrm{N}_{2}$ and $\mathrm{O}_{2}$, whose existence enhances the process of charged-particle recombination, decrease with altitude. However, such a general relationship is based on the assumption that there is no change in the neutral density profiles. Thus, the present observations of increasing plasma height and decreasing plasma density suggest that the dominant reason for the perturbed electron density during disturbed times is related to changes in the neutral densities. Note that both of these changes are consistent with an increase in the scale heights of the neutral species, which is the case when the neutral particles have higher temperatures. The neutral temperature increase can be ultimately due to auroral particle precipitation in association with geomagnetic activity, via the process of transportation from the hot auroral latitudes to the relatively cold middle latitudes by the equatorward neutral wind. From Figures 2-4, the effect of auroral precipitation is the most prominent at lower altitudes. One thus expects the horizontal neutral wind to be generated in the lower F region and probably the E region as well, which correspond to the altitudes where the $\mathrm{N}_{2}$ and $\mathrm{O}_{2}$ molecules are the most abundant species. The increase of the neutral temperature due to the equatorward neutral wind thus raises the scale heights of those molecules in the $\mathrm{E}$ and lower $\mathrm{F}$ regions at lower latitudes, causing a more gentle drop in the density profiles, in equivalence to an uplift of the neutral atmosphere. As a result, the densities of the $\mathrm{N}_{2}$ and $\mathrm{O}_{2}$ molecules in the $\mathrm{F} 2$ region at those latitudes, such as the case at $\lambda_{m}=45^{\circ}-50^{\circ}$, become higher because of the equatorward neutral wind that occurs below. The increase of the densities of those molecules would enhance recombination, leading to a decrease in the electron density and thereby a drop in the peak density. Moreover, because the neutral molecules are more abundant at lower altitudes, the uplift of the atmosphere affects the electron density at lower altitudes more seriously. In other words, the electron density is reduced by a larger extent at lower altitudes, resulting in an upward shift of the hmF2. From the decrease in the peak density in Figure 10a and the increase in the mean hmF2 in Figure 10f during disturbed times, the increase in the neutral scale height due to equatorward neutral wind is a probable explanation for the observation results at $\lambda_{m}=45^{\circ}-50^{\circ}$.

\section{Discussion and conclusions}

We have performed a statistical study on three years of ionospheric vertical EDPs observed during solar minimum by the GOX instrument aboard the F3C satellites, focusing on the effects of geomagnetic activity at subauroral latitudes around the dawn hours. By considering the observations at different SZA ranges, we have found that geomagnetic activity, particularly corresponding to the occurrence of auroras, leads to opposite F2-layer density perturbations in the darkened (predaybreak) and sunlit (post-daybreak) ionosphere. The predaybreak density is enhanced under the condition of strong 
Table 2. Statistically dominant density-perturbing mechanisms associated with geomagnetic activity during the hours of 4-7 MLT .

\begin{tabular}{lllll}
\hline & & & SZA \\
& & $70^{\circ}-90^{\circ}$ & $90^{\circ}-110^{\circ}$ & $110^{\circ}-140^{\circ}$ \\
\hline & $60^{\circ}-65^{\circ}$ & $\mathrm{E}$ & $\mathrm{A}$ & $\mathrm{A}$ \\
& $55^{\circ}-60^{\circ}$ & $\mathrm{E}$ & $\mathrm{A}(\mathrm{MLT} 4-5) / \mathrm{E}($ MLT 5-7) & $\mathrm{A}$ \\
$\lambda_{m}$ & $\mathrm{E}-55^{\circ}$ & $\mathrm{E}$ & $\mathrm{E}$ & $\mathrm{N}$ \\
& $45^{\circ}-50^{\circ}$ & $\mathrm{N}$ & $\mathrm{N}$ &
\end{tabular}

\footnotetext{
${ }^{\text {a }}$ SZA: solar zenith angle; $\lambda_{m}$ : magnetic latitude; MLT: magnetic local time; A: auroral electron precipitation; E: incremental penetration electric field; $\mathrm{N}$ : change in the neutral density profiles, presumably an increase in the neutral scale heights due to equatorward neutral wind during the occurrence of aurora.
}

geomagnetic activity, while the post-daybreak density is reduced. These opposite effects related to the sunlit/darkened condition of the local ionosphere hold at $\lambda_{m}=50^{\circ}-65^{\circ}$ throughout the MLT range considered in this study. These observations of SZA-dependence are useful for space weather studies of the dawnside ionosphere as an indicator of what to anticipate for the density, when known predecessors of periods of high geomagnetic activity, such as interplanetary coronal mass ejections and corotating interaction regions (Smith \& Wolfe, 1976; Gonzalez et al., 1994; Cramer et al., 2013) that are commonly associated with high-speed streams in the interplanetary space (Tsurutani \& Gonzalez, 1987), are observed or expected to occur (Tsurutani et al., 1995).

We have further analyzed the data to identify the statistically dominant mechanisms responsible for the observed density perturbations during disturbed times. By considering how the peak density and the mean hmF2 change in association with geomagnetic activity, we have found that the dominant mechanisms vary by latitude and, at the relatively high subauroral latitudes, by SZA - in certain cases also by MLT - as well. The statistically dominant mechanisms in the latitudinal and SZA ranges considered in this study are summarized in Table 2. At $\lambda_{m}=60^{\circ}-65^{\circ}$, the main effect on the density may come from two physical mechanisms that dominate at different SZA ranges. Auroral particle precipitation, the statistical significance of which during disturbed times is enhanced by the equatorial shift of the auroral region, leads to a positive effect on the density, while the enhanced eastward drifts of the plasma associated with the incremental penetration electric fields may increase or decrease the local density depending on the SZA of the ionosphere. In particular, the enhanced eastward drifts are expected to increase the plasma density in the pre-daybreak SZA range of $110^{\circ}-140^{\circ}$, but may have a positive or negative effect on the density in the partially sunlit ionosphere at $90^{\circ}-110^{\circ} \mathrm{SZA}$. Regardless of which effect of the enhanced eastward drifts, our analysis has found that in those two SZA ranges, the density increase and the change in the mean hmF2 are more reasonably explained by auroral electron precipitation, suggesting that to be the dominant physical mechanism for the density perturbations. At $70^{\circ}-90^{\circ}$ SZA, the two physical mechanisms have opposite effects on the density. Under this post-daybreak condition, incremental penetration electric fields are the dominant density perturbation mechanism associated with geomagnetic activity, causing a net decrease in the local density. We suggest that the dominance of this mechanism over auroral electron precipita- tion is twofold, both related to the high ambient plasma density in the post-daybreak ionosphere. First, the impact of particle precipitation is relatively small under the sunlit condition because of the high ambient density compared with the darkened ionosphere. Second, the zonal density gradient is relatively large at locations with $70^{\circ}-90^{\circ} \mathrm{SZA}$ as a result of the increasing rate of photoionization after daybreak; enhanced eastward drifts of the plasma become a prominent effect on the local density because of the large density gradient. The combination of enhanced eastward drifts and large zonal density gradient apparently affects the local density at $70^{\circ}-90^{\circ}$ SZA more than auroral particle precipitation, making the incremental penetration electric fields the most important physical mechanism on the density perturbations during disturbed times in this SZA range at $\lambda_{m}=60^{\circ}-65^{\circ}$, as suggested by the results of our data analysis.

It is interesting to note that such an interpretation for $70^{\circ}$ $90^{\circ}$ SZA may appear counter-intuitive to the common belief regarding the association between generation of chorus waves and pitch-angle scattering of electrons into the loss cone by these waves from midnight to morning hours in the magnetosphere. But as we shall elaborate later, the apparent disagreement can be readily explained. Such a common belief was established as a result of the consistency found between theories and observations. Tsurutani \& Smith (1977) (TS for short) observed a dependence of magnetospheric chorus events with MLT, in that the chorus was most intense and occurred most frequently in the post-midnight and dawn-to-noon hours at auroral $L$ values. Their observations supported the results of two earlier theoretical studies: The model by Jentsch (1976) showed that electron precipitation in the morning sector of the auroral zone can be interpreted as the consequence of resonant wave-particle interaction involving electrons convecting eastward from a source near midnight and the whistler waves generated by them through instability. Such an interpretation would be consistent with TS's observations of relatively strong intensities and high rates of occurrence of post-midnight chorus. The theory by Brice \& Lucas (1971) (BL for short) suggested that injection of cold ionospheric plasma into the magnetosphere would reduce the stably trapped limit of the hot electrons that interact resonantly with unstable whistler-mode waves. That would correspond to electron cyclotron instability (Brice, 1967) along with an increase of pitch-angle scattering of magnetospheric electrons into the loss cone causing electron precipitation. This effect may be relevant in the post-dawn ionosphere, as sunlight heating could lead to upwelling of 
thermal plasmas, which provide the relatively cold electrons to the magnetosphere. Thus, according to BL's theory, one can expect sunlight to have an effect on the occurrence of chorus waves in the magnetosphere. Such a relationship would be consistent with TS's observations of chorus events regarding the dawn-to-noon sector. In the present study, both enhanced eastward drift of electrons and auroral particle precipitation are in operation at $\lambda_{m}=60^{\circ}-65^{\circ}$. Based on the discussion above, one would expect electron precipitation, rather than enhanced eastward electron drifts, to be the dominant mechanism in the $70^{\circ}-90^{\circ} \mathrm{SZA}$, especially since that is found to be the case in the other two SZA ranges. However, for the numerical example considered in $\mathrm{BL}$, we recognize that the number density of magnetospheric electrons being scattered into the loss cone as a consequence of cold electron injection reducing the stably trapped limit of the hot electrons corresponds to the area enclosed between the curves $\mathscr{F}\left(V_{R}\right)$ and $\mathscr{F}_{\text {max }}\left(V_{R}\right)$ in the plot shown in Figure 3 of their paper, where $\mathscr{F}\left(V_{R}\right) \mathrm{d} V_{R}$ is the number density (in el $/ \mathrm{m}^{3}$ ) of resonating electrons with parallel velocity $V_{R}$ and $\mathscr{F}_{\text {max }}\left(V_{R}\right) \mathrm{d} V_{R}$ is the maximum number density (in $\mathrm{el} / \mathrm{m}^{3}$ ) allowed for those electrons to be stably trapped. We find that while the number density of electrons in the magnetosphere exceeding the stably trapped limit and thus scattered into the loss cone would increase (hence more precipitation) upon an addition of cold electrons, such an increase would be much less than the number density of those additional cold electrons. Suppose the cold electrons injected into the magnetosphere originate from the ionosphere, as in the sunlight-induced situation presumably, the results in BL's example would suggest that the occurrence of electron precipitation in the presence of sunlight is associated with a net loss of electrons in the ionosphere. However, the example represents only one simple model with a specific set of parameters. More investigation is necessary to determine whether or not electron precipitation under sunlit conditions always results in an overall decrease of the ionospheric electron density. Nevertheless, the Brice \& Lucas (1971) model raised the possibility that electron precipitation in the presence of sunlight could correspond to an event in which ionospheric electron density decreases. However, without any solid evidence from the literature of how the overall density in the ionosphere changes in events of sunlight-induced electron precipitation, enhanced eastward plasma drifts due to incremental penetration electric fields remain the most plausible mechanism to dominate the density change in the F2 region at $70^{\circ}-90^{\circ} \mathrm{SZA}, \lambda_{m}=60^{\circ}-65^{\circ}$.

The dominant density perturbation mechanisms at $\lambda_{m}=$ $55^{\circ}-60^{\circ}$ are almost identical to those at $\lambda_{m}=60^{\circ}-65^{\circ}$ in the respective SZA ranges. Incremental penetration electric fields dominate in the sunlit SZA range of $70^{\circ}-90^{\circ}$ and auroral electron precipitation in the darkened ionosphere at $110^{\circ}-140^{\circ}$ SZA. However, for the partially sunlit SZA range of $90^{\circ}-110^{\circ}$, in contrast to the case at $\lambda_{m}=60^{\circ}-65^{\circ}$ where auroral electron precipitation dominates at all the MLT under consideration, there is a split over the MLT ranges at $\lambda_{m}=55^{\circ}-60^{\circ}$ : auroral electron precipitation still dominates at 4-5 MLT, but incremental penetration electric fields take over as the main mechanism at 5-7 MLT. As discussed earlier, the occurrence of auroral electron precipitation at subauroral latitudes during disturbed times is due to equatorial shift of the auroral region. The extent of the shift depends not only on the level of geomagnetic activity, but also on the local time. The statistical study by Hardy et al. (2008) based on observations by Defense Meteorological Satellite Program satellites showed that the equatorial edge of the shifted electron precipitation region was at nearly the same latitude between 4-5 MLT but since then became increasingly poleward as the local time progressed into the morning hours, specifically with estimates of $\lambda_{m}=57.88^{\circ}$, $57.60^{\circ}, 58.60^{\circ}$ and $59.69^{\circ}$ at MLT of $4,5,6$ and 7 , respectively, for $K p=5$. The corresponding $\lambda_{m}$ continues to increase with the MLT and reaches $68.11^{\circ}$ at noon. Therefore, it is probable that at $90^{\circ}-110^{\circ} \mathrm{SZA}$, auroral electron precipitation often extends into the $55^{\circ}-60^{\circ}$ latitudinal range at $4-5$ MLT to dominate the density perturbations during disturbed times; but less likely to reach these latitudes at the later MLT considered in this study, thereby allowing incremental penetration electric fields to become statistically the primary mechanism to perturb the densities.

At further lower latitudes, the situation is simpler in terms of the dominant mechanism associated with geomagnetic disturbances. At $\lambda_{m}=50^{\circ}-55^{\circ}$, incremental penetration electric fields are the dominant density perturbation mechanism throughout the SZA and MLT ranges considered in this study. At $\lambda_{m}=45^{\circ}-50^{\circ}$, a change in the neutral density profiles as the primary reason for the electron density perturbation is consistent with our observations. Such a change for the neutral particles can be due to a temperature increase resulted from the transport of aurora-induced equatorial neutral wind.

Besides plasma transport, enhanced plasma drifts may give rise to another physical effect that is relevant to the electron density: Faster convection leads to more collisions between the ions and the neutrals. Through reactions of charge exchange, $\mathrm{NO}^{+}$and $\mathrm{O}_{2}{ }^{+}$, which have very fast rates of recombination with electrons, are created by collisions between $\mathrm{O}^{+}$and the neutral molecules $\mathrm{N}_{2}$ and $\mathrm{O}_{2}$, respectively. Thus, each additional $\mathrm{O}^{+}-\mathrm{N}_{2}$ or $\mathrm{O}^{+}-\mathrm{O}_{2}$ collision essentially leads to the removal of one additional electron, meaning that increased number of ion-neutral collisions induced by the incremental penetration electric field has a negative effect on the electron density. Such an effect has been studied quantitatively by Schunk et al. (1975) (S75 for short), who adapted a model originally for the mid-latitude ionosphere (Schunk \& Walker, 1973) to investigate the effect of electric fields on the highlatitude ionosphere. Using neutral densities similar to those in the 1973 study, S75 showed that increasing the effective perpendicular electric field, which was defined to be $\mathbf{E}_{\perp}{ }^{\prime}=$ $\mathbf{E}_{\perp}+\mathbf{U}_{\mathbf{n}} \times \mathbf{B}$ in MKS units with $\mathbf{U}_{\mathbf{n}}$ being the neutral wind velocity, resulted in a decrease in the electron density. In particular, the peak electron density decreased by about $10 \%$ when $E_{\perp}$ ' increased from $0-25 \mathrm{mV} / \mathrm{m}$. Using the study by $\mathrm{S} 75$, we can estimate this negative effect on the electron density in our case. First of all, according to Wand \& Evans (1981b), when $K p=5$, the southward component of the incremental electric fields that gives rise to the enhanced eastward plasma drift is $<2 \mathrm{mV} / \mathrm{m}$ in the MLT ranges considered in this study. As mentioned in Section 3, there are also a westward component of the incremental fields and an equatorward neutral wind, with typical values of about $2 \mathrm{mV} / \mathrm{m}$ and $45 \mathrm{~m} / \mathrm{s}$ respectively. Based on the magnetic field at $250 \mathrm{~km}$ altitude above Millstone Hill, which is $47000 \mathrm{nT}$ with an inclination of $71.36^{\circ}$ under a dipole field configuration, the above typical value of the neutral wind would give a purely eastward $\mathbf{U}_{\mathbf{n}} \times \mathbf{B}$ 
of magnitude $2 \mathrm{mV} / \mathrm{m}$, offsetting the contribution by the westward component of the incremental electric fields in the calculation of $\mathbf{E}_{\perp}$ '. For the southward incremental electric fields, assumed to be $2 \mathrm{mV} / \mathrm{m}$ in this calculation, its contribution to $\mathbf{E}_{\perp}$ ' is its component perpendicular to $\mathbf{B}$, which would be $1.90 \mathrm{mV} / \mathrm{m}$ in magnitude. Thus, based on the incremental electric fields and the neutral wind, $E_{\perp}$ ' is estimated to be typically $1.90 \mathrm{mV} / \mathrm{m}$ under the conditions considered in this study. The enhancement of the convection speed due to such an $E_{\perp}$ ' would be smaller than the convection speed in $\mathrm{S} 75$ for $E_{\perp}{ }^{\prime}=25 \mathrm{mV} / \mathrm{m}$ by one order of magnitude. The physical mechanism that causes faster recombination is due to more frequent $\mathrm{O}^{+}-\mathrm{N}_{2}$ and $\mathrm{O}^{+}-\mathrm{O}_{2}$ collisions. From the point of view of an $\mathrm{O}^{+}$ion drifting through a neutral background, the volume traversed by its collision cross section in a given time would be proportional to its speed. Then the number of neutrals in such a volume would also be proportional to its speed. For simplicity, we thus approximate the $\mathrm{O}^{+}$-neutral collision frequency - and the loss rate of electrons due to recombination - to be proportional to the convection speed. With the enhanced convection speed in our case smaller than the convection speed in S75 by about one order of magnitude, we estimate that the reduction in the electron peak density due to the incremental electric fields would be of the order of $1 \%$ in our case. As the density perturbation observed in this study is usually considerably more than $1 \%$, we believe that faster recombination due to enhanced convection speed does not change the conclusion in our study.

In Section 3, we have discussed the approach to compare quiet-time plasma parameters between adjacent MLT ranges of the same SZA and latitude, in order to examine whether the observed changes in the local ionosphere during periods of high geomagnetic activity are consistent with enhanced eastward plasma drifts. We have emphasized that we use the same SZA range to perform the comparison even though sometimes the earlier MLT range may belong to a larger SZA range, so as to avoid overestimating the difference in density. As one checks through Figures 7-10, one can clearly see that the quiet-time $(K p=0-1)$ densities at SZA $70^{\circ}-90^{\circ}$ are indeed much larger than those at $90^{\circ}-110^{\circ}$, which are more often larger than those at $110^{\circ}-140^{\circ}$. Among the ionospheric conditions that favor incremental penetration electric field as the dominant mechanism for density perturbation during disturbed times, as indicated in Table 2, we check whether using the next larger SZA range for the earlier MLT in the quiet-time plasma comparison would change the conclusion, and notice that nearly all of the symbols in the small panels of Figures 7-9 that are relevant to those conditions would still be of the same color. There would be two exceptions, however, that appear to render a color that does not match with the color in the corresponding large panels: Both correspond to peak densities at MLT 5-6, SZA $90^{\circ}-110^{\circ}$ during November to January, with one at $\lambda_{m}=55^{\circ}-60^{\circ}$ (Fig. 8, panel (e)) and the other at $\lambda_{m}=50^{\circ}-55^{\circ}$ (Fig. 9, panel (e)). In both cases, the empty squares would be filled with light-green color as the respective peak densities at MLT $4-5$, SZA $110^{\circ}-140^{\circ}$ are slightly larger, in contrast to the dark-green color at MLT 5-6 in panel (a) of Figures 8 and 9. However, when the weighted averages over the seasons are considered, the quiet-time densities at MLT $4-5$, SZA $110^{\circ}-140^{\circ}$ would be lower than those at MLT $5-6$, SZA $90^{\circ}-110^{\circ}$ by $13.57 \%$ and $6.05 \%$, respectively, at $\lambda_{m}=55^{\circ}-60^{\circ}$ and $\lambda_{m}=50^{\circ}-55^{\circ}$. These results would be qualitatively the same as those based on our approach of using the same SZA range for quiet-time plasma comparison, in support of our conclusion that incremental penetration electric fields are the dominant mechanism for changing the density during disturbed times.

As the EDPs in this study were obtained from RO techniques that utilized the Abel inversion approach, which assumes spherical symmetry of the ionosphere (Schreiner et al., 1999), the accuracy of these profiles could be subject to the influence of horizontal density gradients that are expected particularly during disturbed times. The issue of how geomagnetic activity could affect the EDPs obtained from RO techniques has recently been addressed by Habarulema \& Carelse (2016), who used a statistical approach to compare such profiles at middle latitudes with the corresponding ionosonde observations. They found that over 13 consecutive years of data under the condition of $D s t \leq-50 \mathrm{nT}$, the ROgenerated EDP set on average differed from the ionosonde measurements by $4.2 \%$ in $\mathrm{NmF} 2$ and $9.77 \mathrm{~km}$ in $\mathrm{hmF} 2$, with the respective standard deviations of $20.8 \%$ and $24.82 \mathrm{~km}$. Thus, while an individual EDP generated from RO techniques could be considerably different from the ionosonde observation in terms of $\mathrm{NmF} 2$ and $\mathrm{hmF} 2$, such differences tend to average out to significantly smaller values under the consideration of a large number of EDPs. As shown in Panels (a) and (f) of Figures 7-10, the percentage differences in peak density and the differences in mean $\mathrm{hmF} 2$ are typically larger than the corresponding average discrepancies $(4.2 \%$ and $9.77 \mathrm{~km}$ ) associated with applications of RO techniques during disturbed times. This validates the qualitative results in this statistical study.

From the statistical results and the discussion based on those, we can conclude that in the subauroral-latitude ionosphere near dawn, the dominance of the density perturbation mechanisms in association with geomagnetic activity generally changes from auroral precipitation to incremental penetration electric fields to aurora-induced equatorial neutral wind as the latitude decreases. Each of the three mechanisms, in principle, may affect only a certain range of latitudes equatorward of the quiet-time auroral region. In particular, the relatively high subauroral latitudes of $60^{\circ}-65^{\circ}$ are affected by all three mechanisms. Based on the dominant mechanism in each SZA range at these latitudes, auroral precipitation is the most influential of the three for darkened and partially sunlit ionosphere, as the incremental penetration electric field is for the sunlit ionosphere. The occurrence of auroral precipitation may often extend into magnetic latitudes of $55^{\circ}-60^{\circ}$ as a result of geomagnetic activity, but, from a statistical point of view, rarely to $50^{\circ}-55^{\circ}$, at which the ionosphere is apparently still affected by the incremental penetration electric fields and aurora-induced neutral wind, with the electric fields being the more significant mechanism. From the change of dominant mechanism to neutral wind further equatorward, we can infer that the disturbed-time electric fields seldom penetrate to magnetic latitudes below $50^{\circ}$.

Overall, by performing two data analyses, we have found statistical results that are useful for space weather and space physics researches regarding the effects of geomagnetic 
activity on the ionosphere around the dawn hours. From the point of view of space weather, this study has shown that SZA is a key factor for the change in the ionospheric density under the influence of geomagnetic disturbances. Such a key factor along with support from experimental evidence associated with geomagnetic activity, to our knowledge, has not been reported in the literature prior to this study. From the perspective of space physics, we have identified the statistically dominant density-perturbing mechanisms in various subauroral latitudinal ranges of the ionosphere and provided the physical reasons for those mechanisms. These statistical results can enhance our understanding of the influence of geomagnetic activity on the ionosphere from a non-local point of view, complementing relevant studies that are based on the event approach.

Acknowledgments. The F3C data of EDPs are provided by TACC and UCAR, available at the following URLs: http:// tacc.cwb.gov.tw/ and http://cdaac-www.cosmic.ucar.edu/ cdaac/products.html\#cosmicrt. This work is supported by the Ministry of Science and Technology, R.O.C., under the grant numbers 105-2111-M-006-007 and 104-2111-M032-001-MY2. The editor thanks two anonymous referees for their assistance in evaluating this paper.

\section{References}

Astafyeva E, Zakharenkova I, Alken P. 2016. Prompt penetration electric fields and the extreme topside ionospheric response to the June 22-23, 2015 geomagnetic storm as seen by the Swarm constellation. Earth, Planets and Space 68: 152. DOI: 10.1186/ s40623-016-0526-x.

Basu S, Basu S, Valladares CE, Yeh H-C, Su S-Y, MacKenzie E, Sultan PJ, Aarons J, Rich FJ, Doherty P, Groves KM, Bullett TW. 2001. Ionospheric effects of major magnetic storms during the International Space Weather Period of September and October 1999: GPS observations, VHF/UHF scintillations, and in situ density structures at middle and equatorial latitudes. J Geophys Res 106: 30389-30413. DOI: 10.1029/2001JA001116.

Bell TF. 1985. High-amplitude VLF transmitter signals and associated sidebands observed near the magnetic equatorial plane on the ISEE-1 satellite. J Geophys Res 90: 2792-2806. DOI: 10.1029/JA090iA03p02792.

Brace LH, Maier EJ, Hoffman JH, Whitteker J, Shepherd GG. 1974. Deformation of the night side plasmasphere and ionosphere during the August 1972 geomagnetic storm. J Geophys Res 79: 52115218. DOI: 10.1029/JA079i034p05211.

Brice N. 1967. Bulk motion of the magnetosphere. J Geophys Res 72 : 5193-5211. DOI: 10.1029/JZ072i021p05193.

Brice N, Lucas C. 1971. Influence of magnetospheric convection and polar wind on loss of electrons from the outer radiation belt. $J$ Geophys Res 76: 900-908. DOI: 10.1029/JA076i004p00900.

Buonsanto MJ. 1999. Ionospheric storms - a review. Space Sci Rev 88: 563-601. DOI: 10.1023/A:1005107532631.

Cai HT, Yin F, Ma SY, Xu JS, Liu YW. 2012. Simultaneous observations of large-scale traveling ionospheric disturbances on the nightside and dayside middle latitude. Ann Geophys 30: 17091717. DOI: 10.5194/angeo-30-1709-2012.

Cheng C.-Z.F, Kuo YH, Anthes RA, Wu L. 2006. Satellite constellation monitors global and space weather. Eos Trans AGU 87 (17): 166-166. DOI: 10.1029/2006EO170003.
Cramer WD, Turner NE, Fok M-C, Buzulukova NY. 2013. Effects of different geomagnetic storm drivers on the ring current: CRCM results. J Geophys Res: Space Phys 118: 1062-1073. DOI: 10.1002/jgra.50138.

Emmert JT, Fejer BG, Shepherd GG, Solheim BH. 2004. Average nighttime $\mathrm{F}$ region disturbance neutral winds measured by UARS WINDII: Initial results. Geophys Res Lett 31: L22807. DOI: 10.1029/2004GL021611.

Foster JC. 1993. Storm time plasma transport at middle and high latitudes. J Geophys Res 98: 1675-1689. DOI: 10.1029/ 92JA02032.

Goncharenko L, Salah J, Crowley G, Paxton LJ, Zhang Y, Coster A, Rideout W, Huang C, Zhang S, Reinisch B, Taran V. 2006. Large variations in the thermosphere and ionosphere during minor geomagnetic disturbances in April 2002 and their association with IMF $B_{y} . J$ Geophys Res 111: A03303. DOI: 10.1029/ 2004JA010683.

Gonzalez WD, Joselyn JA, Kamide Y, Kroehl HW, Rostoker G, Tsurutani BT, Vasyliunas VM. 1994. What is a geomagnetic storm? J Geophys Res 99: 5771-5792. DOI: 10.1029/93JA02867.

Habarulema JB, Carelse SA. 2016. Long-term analysis between radio occultation and ionosonde peak electron density and height during geomagnetic storms. Geophys Res Lett 43: 4106-4111. DOI: 10.1002/2016GL068944.

Hardy DA, Holeman EG, Burke WJ, Gentile LC, Bounar KH. 2008. Probability distributions of electron precipitation at high magnetic latitudes. J Geophys Res 113: A06305. DOI: 10.1029/ 2007JA012746.

Heelis RA, Sojka JJ, David M, Schunk RW. 2009. Storm time density enhancements in the middle-latitude dayside ionosphere. $J$ Geophys Res 114: A03315. DOI: 10.1029/2008JA013690.

Jentsch V. 1976. Electron precipitation in the morning sector of the auroral zone. J Geophys Res 81: 135-146. DOI: 10.1029/ JA081i001p00135.

Jones KL, Rishbeth H. 1971. The origin of storm increases of midlatitude F-layer electron concentration. J Atmos Terr Phys 33: $391-$ 401. DOI: 10.1016/0021-9169(71)90144-9.

Klimenko MV, Klimenko VV, Ratovsky KG, Goncharenko LP. 2012. Numerical modeling of the global ionospheric effects of storm sequence on September 9-14, 2005-comparison with IRI model. Earth, Planets and Space 64: 433-440. DOI: 10.5047/ eps.2011.06.048.

Makita K, Meng C-I, Akasofu S-I. 1983. The shift of the auroral electron precipitation boundaries in the dawn-dusk sector in association with geomagnetic activity and interplanetary magnetic field. J Geophys Res 88: 7967-7981. DOI: 10.1029/JA088i A10p07967.

Mikkelsen IS. 1975. Enhancements of the auroral zone ionization during substorms. Planet. Space Sci 23: 619-626. DOI: 10.1016/ 0032-0633(75)90102-6.

Ngwira CM, McKinnell L-A, Cilliers PJ, Coster AJ. 2012. Ionospheric observations during the geomagnetic storm events on 24-27 July 2004: Long-duration positive storm effects. $J$ Geophys Res 117: A00L02. DOI: 10.1029/2011JA016990.

Pavlov AV, Buonsanto MJ. 1997. Comparison of model electron densities and temperatures with Millstone Hill observations during undisturbed periods and the geomagnetic storms of 16-23 March and 6-12 April 1990. Ann Geophys 15: 327-344. DOI: 10.1007/ s00585-997-0327-4.

Prölss GW, Jung MJ. 1978. Travelling atmospheric disturbances as a possible explanation for daytime positive storm effects of moderate duration at middle latitudes. J Atmos Terr Phys 40: 1351-1354. DOI: 10.1016/0021-9169(78)90088-0. 
Richards PG. 1995. Effects of auroral electron precipitation on topside ion outflows. In: Cross-Scale Coupling in Space Plasmas, Geophysical Monograph 93, pp. 121-126. DOI: 10.1029/GM093p0121.

Schreiner WS, Sokolovskiy SV, Rocken C, Hunt DC. 1999. Analysis and validation of GPS/MET radio occultation data in the ionosphere. Radio Sci 34: 949-966. DOI: 10.1029/1999RS900034.

Schunk RW, Walker JCG. 1973. Theoretical ion densities in the lower ionosphere. Planet Space Sci 21: 1875-1896. DOI:10.1016/ 0032-0633(73)90118-9.

Schunk RW, Raitt WJ, Banks PM. 1975. Effect of electric fields on the daytime high-latitude E and F regions. J Geophys Res 80: 31213130. DOI:10.1029/JA080i022p03121.

Shagimuratov II, Baran LW, Wielgosz P, Yakimova GA. 2002. The structure of mid- and high-latitude ionosphere during September 1999 storm event obtained from GPS observations. Ann Geophys 20: 655-660. DOI: 10.5194/angeo-20-655-2002.

Smith EJ, Wolfe JH. 1976. Observations of interaction regions and corotating shocks between one and five AU: Pioneers 10 and 11. Geophys Res Lett 3: 137-140. DOI: 10.1029/GL003i003p00137.

Stern DP. 1979. The electric field and global electrodynamics of the magnetosphere. Rev Geophys Space Phys 17: 626-640. DOI: 10.1029/RG017i004p00626.

Taeusch DR, Carignan GR, Reber CA. 1971. Neutral composition variation above 400 kilometers during a magnetic storm. J Geophys Res 76: 8318-8325. DOI: 10.1029/JA076i034p08318.
Thomas L, Norton RB. 1966. Possible importance of internal excitation in ion-molecule reactions in the F region. J Geophys Res 71: 227-230. DOI: 10.1029/JZ071i001p00227.

Tsurutani BT, Gonzalez WD. 1987. The cause of high-intensity longduration continuous AE activity (HILDCAAS): Interplanetary Alfvén wave trains. Planet Space Sci 35: 405-412. DOI: 10.1016/ 0032-0633(87)90097-3.

Tsurutani BT, Smith EJ. 1977. Two types of magnetospheric ELF chorus and their substorm dependences. J Geophys Res 82: 5112-5128. DOI: 10.1029/JA082i032p05112.

Tsurutani BT, Gonzalez WD, Gonzalez ALC, Tang F, Arballo JK, Okada M. 1995. Interplanetary origin of geomagnetic activity in the declining phase of the solar cycle. J Geophys Res 100: 21717-21733. DOI: 10.1029/95JA01476.

Wand RH, Evans JV. 1981a. Seasonal and magnetic activity variations of ionospheric electric fields over Millstone Hill. $J$ Geophys Res 86: 103-118. DOI: 10.1029/JA086iA01p00103.

Wand RH, Evans JV. 1981b. The penetration of convection electric fields to the latitude of Millstone Hill $\left(\Lambda=56^{\circ}\right)$. J Geophys Res 86: 5809-5814. DOI: 10.1029/JA086iA07p05809.

Wang K, Tam SWY. 2010. Analysis of ionospheric electron parameters versus geomagnetic index Dst from RO data of FORMOSAT-3/COSMIC. GPS Solutions 14: 99-108. DOI: $10.1007 / \mathrm{s} 10291-009-0148-\mathrm{x}$.

Cite this article as: Tam SWY, Chen C-H, Wang K. 2017. Variations of topside ionospheric electron density near the dawn terminator in relation to geomagnetic activity. J. Space Weather Space Clim. 7: A31 